This is the final peer-reviewed accepted manuscript of:

Simona Arrighi, Eugenio Bortolini, Laura Tassoni, Andrea Benocci, Giuseppe Manganelli, Vincenzo Spagnolo, Luca Maria Foresi, Anna Maria Bambini, Federico Lugli, Federica Badino, Daniele Aureli, Francesco Boschin, Carla Figus, Giulia Marciani, Gregorio Oxilia, Sara Silvestrini, Anna Cipriani, Matteo Romandini, Marco

Peresani, Annamaria Ronchitelli, Adriana Moroni, Stefano Benazzi

\title{
Backdating systematic shell ornament making in Europe to 45,000 years ago
}

Archaeological and Anthropological Sciences

The final published version is available online at:

https://doi.org/10.1007/s12520-019-00985-3

\section{Rights / License:}

The terms and conditions for the reuse of this version of the manuscript are specified in the publishing policy. For all terms of use and more information see the publisher's website.

9 
Simona Arrighi ${ }^{\mathrm{a}, \mathrm{b}, \mathrm{c}^{*}}$, Eugenio Bortolini ${ }^{\mathrm{a}}$, Laura Tassoni ${ }^{\mathrm{d}}$, Andrea Benocci $^{\mathrm{b}}$,Giuseppe Manganelli ${ }^{\mathrm{b}}$, Vincenzo Spagnolo $^{\mathrm{b}, \mathrm{c}}$, Luca Maria Foresi ${ }^{\mathrm{b}}$, Anna Maria Bambini ${ }^{\mathrm{b}}$, Federico Lugli ${ }^{\mathrm{a}, \mathrm{e}}$, Federica Badino $^{\mathrm{a}, \mathrm{f}}$, Daniele Aureli ${ }^{\mathrm{b}, \mathrm{c}, \mathrm{g}}$, Francesco Boschin ${ }^{\mathrm{b}, \mathrm{c}}$, Carla Figus ${ }^{\mathrm{a}}$, Giulia Marciani ${ }^{\mathrm{a}, \mathrm{b}}$, Gregorio Oxilia $^{\mathrm{a}}$, Sara Silvestrini ${ }^{\mathrm{a}}$, Anna Cipriani ${ }^{\mathrm{e}, \mathrm{h}}$, Matteo Romandini ${ }^{\mathrm{a}, \mathrm{d}}$, Marco Peresani ${ }^{\mathrm{d}}$, Annamaria Ronchitelli $^{\mathrm{b}} \&$ Adriana Moroni $^{\mathrm{b}, \mathrm{c}, \mathrm{i}}$, Stefano Benazzi ${ }^{\mathrm{a}, \mathrm{j}}$

\section{Backdating systematic shell ornament making in Europe to 45,000 years ago}

${ }^{a}$ Dipartimento di Beni Culturali, Università di Bologna,48 121 Ravenna, Italy, ${ }^{b}$ Dipartimento di Scienze Fisiche della Terra e dell'Ambiente, Università di Siena, 53100 Siena, Italy ${ }^{\mathrm{c}}$ Centro Studi sul Quaternario, 52037 Sansepolcro, Italy, ${ }^{\mathrm{d}}$ Dipartimento di Studi Umanistici, Università di Ferrara, 44100 Ferrara, Italy, ${ }^{\mathrm{e}}$ Dipartimento di Scienze Chimiche e Geologiche, Università di Modena e Reggio Emilia, 41125 Modena, ${ }^{\mathrm{f}}$ C.N.R. - Istituto per la Dinamica dei Processi Ambientali, 20126 Milano, Italy, ${ }^{\mathrm{g}}$ UMR 7041 ArScAn Equipe An-TET, Université Parigi Ouest Nanterre La Défense,

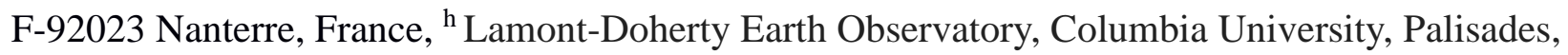
New York, 10964, USA, ${ }^{\text {i }}$ Istituto Italiano di Paleontologia Umana, 03012 Anagni (FR), Italy, ${ }^{\text {j }}$ Department of Human Evolution Max Planck Institute for Evolutionary Anthropology, 04103 Leipzig, Germany.

*Corresponding author (e-mail: simona.arrighi@unibo.it)

\section{Abstract}

Personal ornaments are commonly linked to the emergence of symbolic behaviour. Although their presence in Africa dates back to the Middle Stone Age, evidence of ornament manufacturing in 
Eurasia are sporadically observed in Middle Palaeolithic contexts, and until now large scale diffusion has been until now well documented only since the Upper Palaeolithic.

Nevertheless, little is known during the period between ca.50,000 and 40,000 years ago (ka), when modern humans colonized Eurasia replacing existing hominin populations such as the Neandertals, and a variety of so called "transitional" and/or early Upper Palaeolithic cultures emerged. Here we present shell ornaments from the Uluzzian site of Grotta del Cavallo in Italy, southern Europe. Our results show evidence of a local production of shell beads for ornamental purposes as well as a trend toward higher homogeneity in tusk bead shape and size over time. The temporal interval of the layers of interest (45-40 ka) makes Cavallo the earliest known shell ornament making context in Europe.

Key words: Uluzzian, Italy, Grotta del Cavallo, shell ornaments

\section{Introduction}

The use of personal ornaments in human history is a key issue to understand the evolutionary processes that led to modern humankind beyond a biological perspective. Over the past decades various hypotheses have been expressed on this topic, based on the different perspectives of anthropology, ethnography, sociology, and linguistics (White 1989; d'Errico et al. 2003a; McElreath et al. 2003; Abadia and Nowell 2015).

Personal adornments are interpreted as markers of population structure from a cultural/linguistic and social point of view since the beginning of the Upper Palaeolithic (Vanhaeren and d'Errico 2006; Stiner et al. 2013), but they are also proof of an initial aesthetic perception (Leroi-Gourhan 1964) and their presence is the best archaeological evidence of shared symbolic language linked to individual appearance (White 1989; d'Errico et al. 2003a). Unfortunately, the vast majority of deliberate body modifications (including tattoos, scarifications, ear piercing, lip and neck stretching 
and other numerous kinds of alterations aimed to modify one's own physical appearance) are embedded in perishable materials and cannot be retrieved from Palaeolithic contexts. This makes high concentrations of non-functional elements - such as the one presented here - even more relevant and informative on the emergence of socially recognized symbolic expressions (which may or may not have involved other kinds of body alterations).

The earliest known evidence of ornaments is associated with Modern Humans (MHs), and dates back to 135-70 ka in Africa and in the Levant (Vanhaeren et al. 2006; d'Errico et al. 2009; Vanhaeren et al. 2013; d'Errico and Backwell 2016). In the latter region, evidence of personal ornaments is still consistently found in the period ranging from the Levantine Middle to Upper Palaeolithic (Bosch et al. 2019), while there is broad consensus on the fact that, in Europe, the systematic production of ornaments became a substantial component of material culture since the Protoaurignacian, an Upper Palaeolithic culture dated between 42-36 ka and confidently attributed to $\mathrm{MH}$ (Benazzi et al. 2015). There is no doubt, however, that during the Middle to Upper Palaeolithic transition (50-40 ka) ornaments were already becoming more common in the region. Such a trend documents a change in human social behavior compared to the scanter evidence of ornaments derived from animals and seashells attested in Middle Palaeolithic contexts attributed to Neandertals (Peresani et al. 2011; Peresani et al. 2013; Romandini et al. 2014; Radovčić et al. 2015; Hoffmann et al. 2018).

In this timeframe late Neandertals and the newly arrived modern human groups coexisted in Europe, and the archaeological record shows the emergence of new techno-complexes (the socalled transitional complexes) which exhibit a number of innovative features (such as formal bone tools manufacturing, the systematic use of ornaments and pigments, etc...) compared to late Mousterian assemblages (d’Errico et al. 2003a, 2003b; Zilhão 2006; Flas 2011; Boscato and Crezzini 2012; d'Errico and Banks 2013; Moroni et al. 2013 and 2018; Škardla, 2013; Hublin 2015). Attribution of transitional industries to either Neandertals or modern humans is often difficult because of the scarcity of human fossils found in association with elements of the material 
culture. Labelling these industries as "transitional" entails that they express admixed Middle and Upper Palaeolithic features and are the product of late Neandertal groups which interacted with modern humans or independently acquired modern behaviours (Hublin 2015).

More recent research, however, questioned (Bar-Yosef 2007; Bar-Yosef and Bordes 2010; Benazzi et al. 2011; Moroni et al. 2013 and 2018; Gravina et al. 2018) the association of Neandertals with both Uluzzian (Zilhão et al. 2015, Villa et al. 2018) and Châtelperronian material cultures (Lévêque and Vandermeersch 1980; Hublin et al. 1996; Welker et al. 2016). In particular, the Uluzzian is now considered to be made by modern humans (Benazzi et al. 2011, Moroni et al. 2013 and 2018; Sano et al. 2019 but see contra Zilhao et al. 2015, Villa et al. 2018) on the basis of two deciduous teeth recovered at Grotta del Cavallo and attributed to Homo sapiens. Uluzzian assemblages display explicitly modern elements, such as the systematic presence of bone tools, colouring substances, ornaments, and a lithic technology that does not show any evidence of continuity with the Mousterian technological tradition (Ronchitelli et al. 2009; d'Errico et al. 2012; Peresani et al. 2016; Moroni et al. 2018; Peresani et al. 2019a; Sano et al. 2019).

Archaeological assemblages of continental Europe dated to the Middle to Upper Palaeolithic shift yielded sporadic evidence of ornaments and ornament manufacturing on animal bone and teeth (d'Errico et al. 1998; Zilhão 2007), with the exception of Châtelperronian contexts in France which also included a few seashells (Zilhão 2007) (Fig.1). On the other hand, personal ornaments uncovered in Uluzzian assemblages ( 45-40 ka) of Mediterranean Europe only consist of seashells (Palma di Cesnola 1989; Fiocchi 1998; Stiner 2010). Findings of this kind are present and sometimes abundant at Klissoura (Greece; $n=32$ ), Grotta della Cala (southern Italy; $n=30$ ), and Riparo Broion (northern Italy; $\mathrm{n}=6$ ). Grotta del Cavallo (southern Italy) stands absolutely out with 531 seashells distributed across the entire Uluzzian sequence, dated between 45.5 - $39.9 \mathrm{ka}$ (Benazzi et al. 2011; Douka et al. 2014; Moroni et al. 2018). 


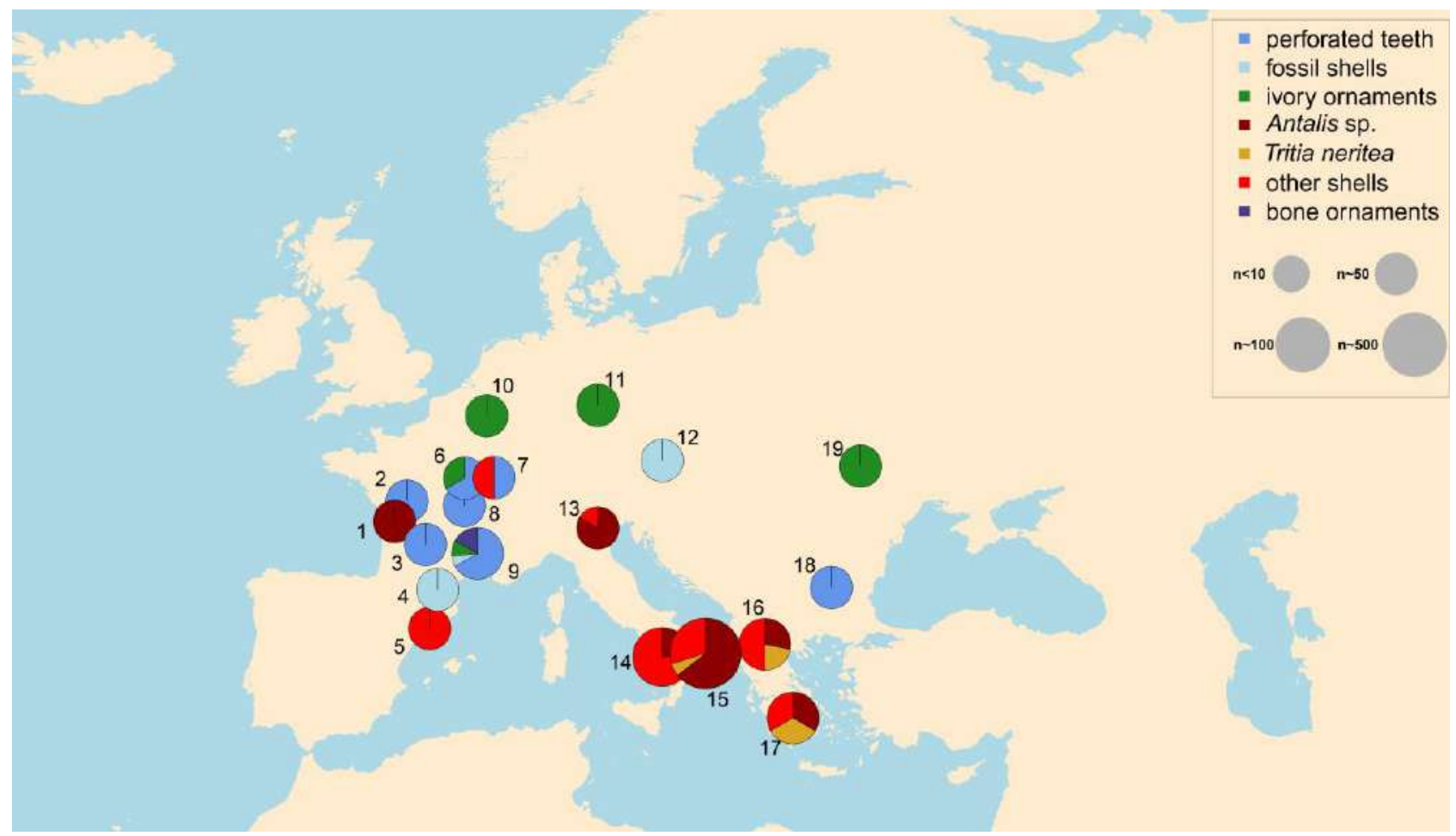

Fig. 1 Distribution of ornaments dated between ca. 45 and 39 ka across transitional contexts in Europe (sites with debated cultural attribution are represented here, see "Discussion" section). Pie radius is proportional to the total size of ornamental assemblages, while colors indicate the relative proportion contributed by different classes of items. (1) Saint-Césaire, (2) Quinçay, (3) Roc de Combe, (4) Caune de Belvis, (5) Cova Foradada, (6) Roche au Loup, (7) Grotte du Trilobite, (8) Grotte des Fées, (9) Grotte du Renne, (10) Trou Magrite, (11) Ilsenhöle Ranis, (12) Willendorf II, (13) Riparo Broion, (14) Grotta della Cala, (15) Grotta del Cavallo, (16)Klissoura Cave, (17) Franchthi Cave, (18) Bacho Kiro, (19) Brynzeny I

Nonetheless, a systematic study of the Uluzzian shell assemblage was never undertaken. The abundance of shell beads found at Grotta del Cavallo offers a privileged perspective for a systematic reassessment of ornament making in this and other Uluzzian assemblages. The key question is therefore to understand whether systematic manufacturing and personal use of shell beads took place at the site, and therefore if Cavallo back dates to $45 \mathrm{ka}$ the beginning of one of the most salient traits of Upper Palaeolithic Europe.

Here we present a thorough analysis of the entire sequence of shell assemblages found in the Uluzzian layers at Grotta del Cavallo. At this site the Uluzzian can be followed from the archaic 
(layer EIII) to the evolved-late phase (layer EII-I and D), sandwiched by the tephra Y-6 at $45.5 \pm 1.0$ ka (Zanchetta et al. 2018) and Y-5 (Campanian Ignimbrite) at $39.85 \pm 0.14 \mathrm{ka}$ (Giaccio et al. 2017; Zanchetta et al. 2018). All dates obtained from shells (5 Antalis sp. from EII-I, spit E-D, DII and DIIb, 1 Lembulus pella from DIIb - Benazzi et al. 2011) are consistent with the chronological frame established by the above mentioned tephra layers. Previous works maintained that the presence in the Uluzzian deposit of important post-depositional disturbances might undermine the association between Uluzzian assemblage and modern humans (Gioia 1990; Zilhão 2007; Zilhão et al. 2015). Nevertheless, more recent research has definitely confirmed the integrity of the archaeological deposit in which the teeth attributed to MHs were recovered and therefore the reliability of their association with the Uluzzian materials (Moroni et al. 2018; Zanchetta et al. 2018; see Supplementary Information Appendix, Section I).

Here, we ascertain the presence of anthropogenic intervention on scaphopods (also known as tusk shells), gastropods, and bivalves as well as their use as personal ornaments through the combined use of quantitative analysis of morphology, experimental tests, use-wear, $\mathrm{Sr}$ isotopes, and micropalaeontological examination. Results, which are compared with the broader picture emerging from other Uluzzian contexts, show evidence of an increasing regularity in shape and size of the beads, as well as of their local production for ornamental purposes.

\section{Materials - The shell assemblage from Grotta del Cavallo}

The Uluzzian layers of Cavallo yielded 618 shell remains (531 NISP), mostly retrieved in the uppermost layers DII and DI. Among them, 285 can be assigned to 32 taxa (Table 1 and Fig. 2) while the majority is still undetermined due to their bad state of preservation. Among identified classes, scaphopods are the most represented and ubiquitous one across the entire sequence, while gastropods and bivalves are considerably less abundant and clustered in the upper layers DI and DII ( $\mathrm{n}=124$, of which 28 are pierced). The lowermost Uluzzian layer yielded, in addition to 67 
scaphopods, 7 bivalves and 33 gastropods, one of which consists of a pierced Tritia neritea

168 (Fig.2b). Species richness increases over time and reaches its maximum in the uppermost layers with 22 identified species encompassing both edible and not edible species. The most represented species are Tritia neritea, Lembulus pella and Glycymeris sp.

\begin{tabular}{|c|c|c|c|c|c|c|c|}
\hline Taxa & E III & EII-I & E-D & DII & DI & $\mathrm{D}$ (DI+DII) & Total \\
\hline Gasteropode undet. & 21 & - & - & - & - & - & 21 \\
\hline Patella rustica * & 2 & - & - & - & - & - & 2 \\
\hline Jujubinus striatus & - & - & - & - & 2 & - & 2 \\
\hline Phorcus sp. & - & - & - & - & 1 & - & 1 \\
\hline Phorcus turbinatus * & - & - & - & $1(1)$ & - & - & $1(1)$ \\
\hline Homalopoma sanguineum & - & - & - & 2 & $8(1)$ & $1(1)$ & $11(2)$ \\
\hline Bittium reticulatum & 1 & - & - & - & - & - & 1 \\
\hline Cerithium sp. & - & - & - & - & 1 & 2 & 3 \\
\hline Cerithium vulgatum * & 3 & - & - & - & 1 & 1 & 5 \\
\hline Turritella sp. & 3 & - & - & - & 2 & 2 & 7 \\
\hline Melaraphe neritoides & 1 & - & - & - & - & - & 1 \\
\hline Trivia pulex & - & - & - & - & 1 & - & 1 \\
\hline Naticarius hebraeus * & 1 & 1 & - & - & - & - & 2 \\
\hline Euspira catena & - & - & 1 & - & 1 & - & 2 \\
\hline Aporrhais pespelecani* & - & - & - & 1 & - & - & 1 \\
\hline Tritia sp. & - & - & - & - & - & 1 & 1 \\
\hline Tritia cuvierii/unifasciata & - & - & - & - & 2 & - & 2 \\
\hline Tritia neritea & $1(1)$ & - & - & $5(4)$ & $22(5)$ & $4(2)$ & $32(12)$ \\
\hline Tritia nitida & - & - & - & $1(1)$ & - & - & $1(1)$ \\
\hline Columbella rustica $*$ & - & - & - & - & 1 & $2(1)$ & $3(1)$ \\
\hline Total gastropods & $33(1)$ & 1 & 1 & $10(6)$ & $42(6)$ & 13 (4) & $100(17)$ \\
\hline Lembulus pella & - & - & - & - & $10(10)$ & - & $10(10)$ \\
\hline Mytilus galloprovincialis * & - & - & - & - & 27 & - & 27 \\
\hline
\end{tabular}




\begin{tabular}{|l|c|c|c|c|c|c|c|}
\hline Glycymeris sp. & 1 & - & - & 2 & $13(2)$ & 1 & $\mathbf{1 7}(\mathbf{2})$ \\
\hline Glycymeris nummaria $^{*}$ & - & - & - & - & - & 1 & $\mathbf{1}$ \\
\hline Pecten jacobaeus $^{*}$ & - & - & - & - & 1 & - & $\mathbf{1}$ \\
\hline Spondylus gaederopus * & - & - & 1 & - & - & - & $\mathbf{1}$ \\
\hline Acanthocardia sp. * & 6 & - & - & - & 1 & - & $\mathbf{7}$ \\
\hline Callista chione * & - & 1 & - & - & 2 & - & $\mathbf{3}$ \\
\hline Corbula gibba & - & - & - & - & 1 & - & $\mathbf{1}$ \\
\hline Total bivalves & $\mathbf{7}$ & $\mathbf{1}$ & $\mathbf{1}$ & $\mathbf{2}$ & $\mathbf{5 5}(\mathbf{1 2})$ & $\mathbf{2}$ & $\mathbf{6 8}(\mathbf{1 2})$ \\
\hline Antalis sp. & 10 & 11 & 13 & 63 & 72 & 77 & $\mathbf{2 4 6}$ \\
\hline Antalis vulgaris & 32 & 1 & 2 & 23 & 15 & 6 & $\mathbf{7 9}$ \\
\hline Antalis dentalis/inaequicostata & 25 & 6 & 2 & 1 & - & 3 & $\mathbf{3 7}$ \\
\hline Fissidentalium rectum & - & - & - & - & - & 1 & $\mathbf{1}$ \\
\hline Total scaphopods & $\mathbf{6 7}$ & $\mathbf{1 8}$ & $\mathbf{1 7}$ & $\mathbf{8 7}$ & $\mathbf{8 7}$ & $\mathbf{8 7}$ & $\mathbf{3 6 3}$ \\
\hline Total NISP & $\mathbf{1 0 7}$ & $\mathbf{2 0}$ & $\mathbf{1 9}$ & $\mathbf{9 9}$ & $\mathbf{1 8 4}$ & $\mathbf{1 0 2}$ & $\mathbf{5 3 1}$ \\
\hline Undetermined & $\mathbf{2 4}$ & $\mathbf{1 9}$ & $\mathbf{9 9}$ & $\mathbf{2 3 6}$ & $\mathbf{1 2 5}$ & $\mathbf{6 1 8}$ \\
\hline Total NR & & - & - & 52 & 23 & 87 \\
\hline
\end{tabular}

Table 1 Malacological assemblage from Grotta del Cavallo. Edible species are marked with an asterisk. Numbers in brackets are for pierced specimens. The taxonomic analysis is based on the updated datasets available online on the World Register of Marine Species (WoRMS; www.marinespecies.org), also the number of rests (NR) and the number of identified specimens (NISP) have been used in order to define the right amount of the assemblage

Shells from layer EIII were mostly found in an area of about 4 square meters (squares E 13, F11, F12 and G 11) (94.1\%) while only 5.9\% comes from the 1963-66 excavation trench corresponding to an area of about 2.5-3 x 3.5 m (Moroni et al., 2018) (Table 2; see SI Appendix, Section I for details and Fig.S1). 


\begin{tabular}{|c|c|c|c|c|c|c|c|}
\hline & EIII & EII-I & E-D & DII & DI & D whole & Total \\
\hline $\begin{array}{l}\text { E-F-G8*; E-F9*; E-F10* } \\
\text { (1963-66 } \\
\text { excavation trench) }\end{array}$ & $5(4)$ & $5(5)$ & - & $21(17)$ & 3 & - & $34(26)$ \\
\hline E13* & $17(1)$ & - & - & - & - & - & $17(1)$ \\
\hline E11 & 2 & - & - & - & - & - & 2 \\
\hline F13* & - & - & - & - & - & - & - \\
\hline F12* & $12(4)$ & - & - & - & - & - & $12(4)$ \\
\hline F11* & $18(12)$ & - & - & - & - & - & $18(12)$ \\
\hline G11* & $59(46)$ & - & - & - & - & - & $59(46)$ \\
\hline G10* & - & - & - & - & - & - & - \\
\hline G7 & - & - & - & - & - & - & - \\
\hline H11 & - & $17(13)$ & $17(15)$ & $78(70)$ & $233(87)$ & $102(74)$ & 447 (259) \\
\hline $\mathrm{H} 8 *$ & - & - & - & - & - & - & - \\
\hline $\mathrm{H} 7 *$ & 2 & 2 & $2(2)$ & & & $23(13)$ & $29(15)$ \\
\hline Total & $115(67)$ & $24(18)$ & $19(17)$ & $99(87)$ & $236(87)$ & $125(87)$ & $618(363)$ \\
\hline
\end{tabular}

Shells from layer EII-I were retrieved in square H11 and in the 1963-1966 excavation trench (Table 2). Shells from layers DII and DI come almost exclusively from two square meters (H11 and H7 Fig. S1). Only very few specimens from both layers were found in the 1963-66 excavation trench (Table 2). 

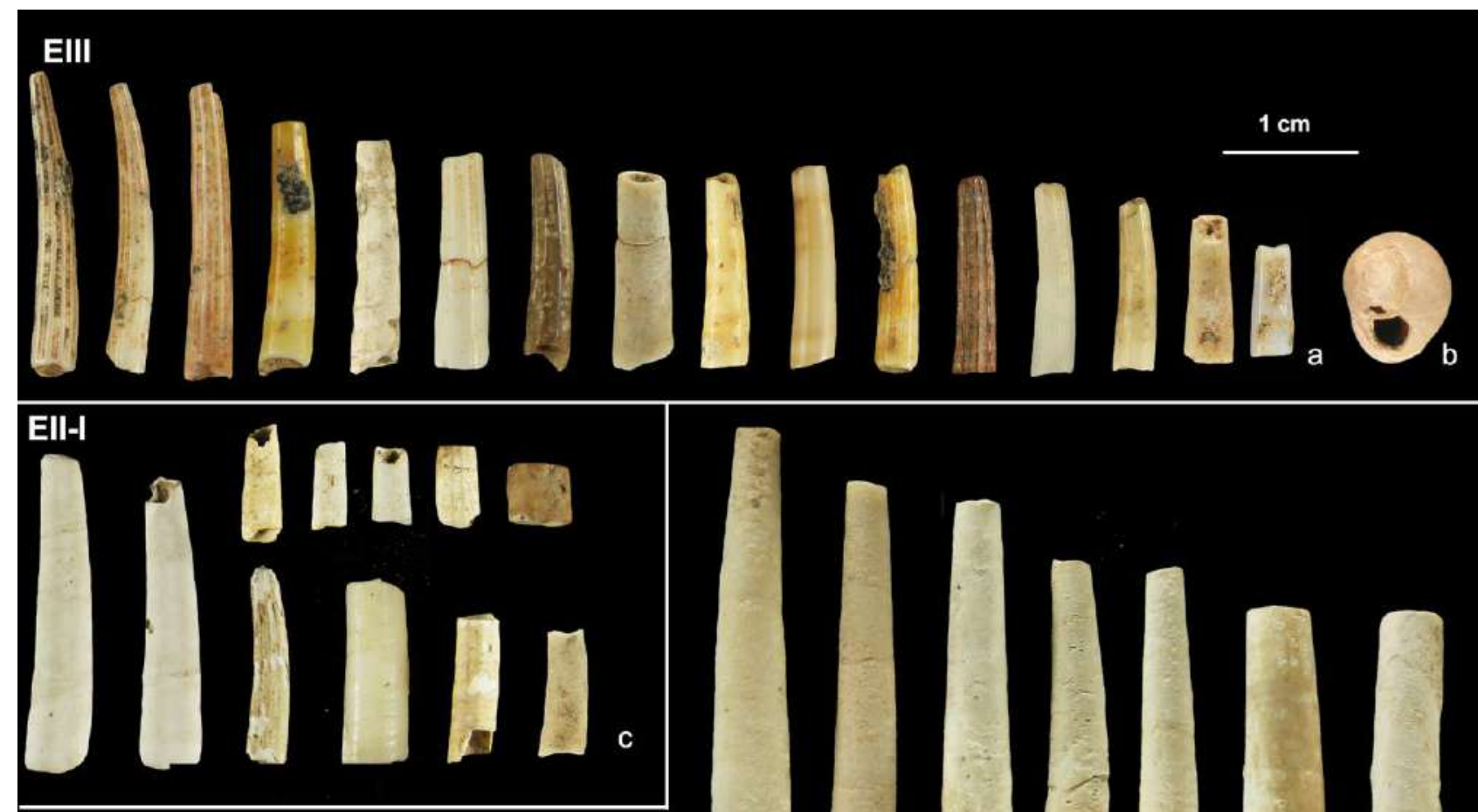

DII - DI
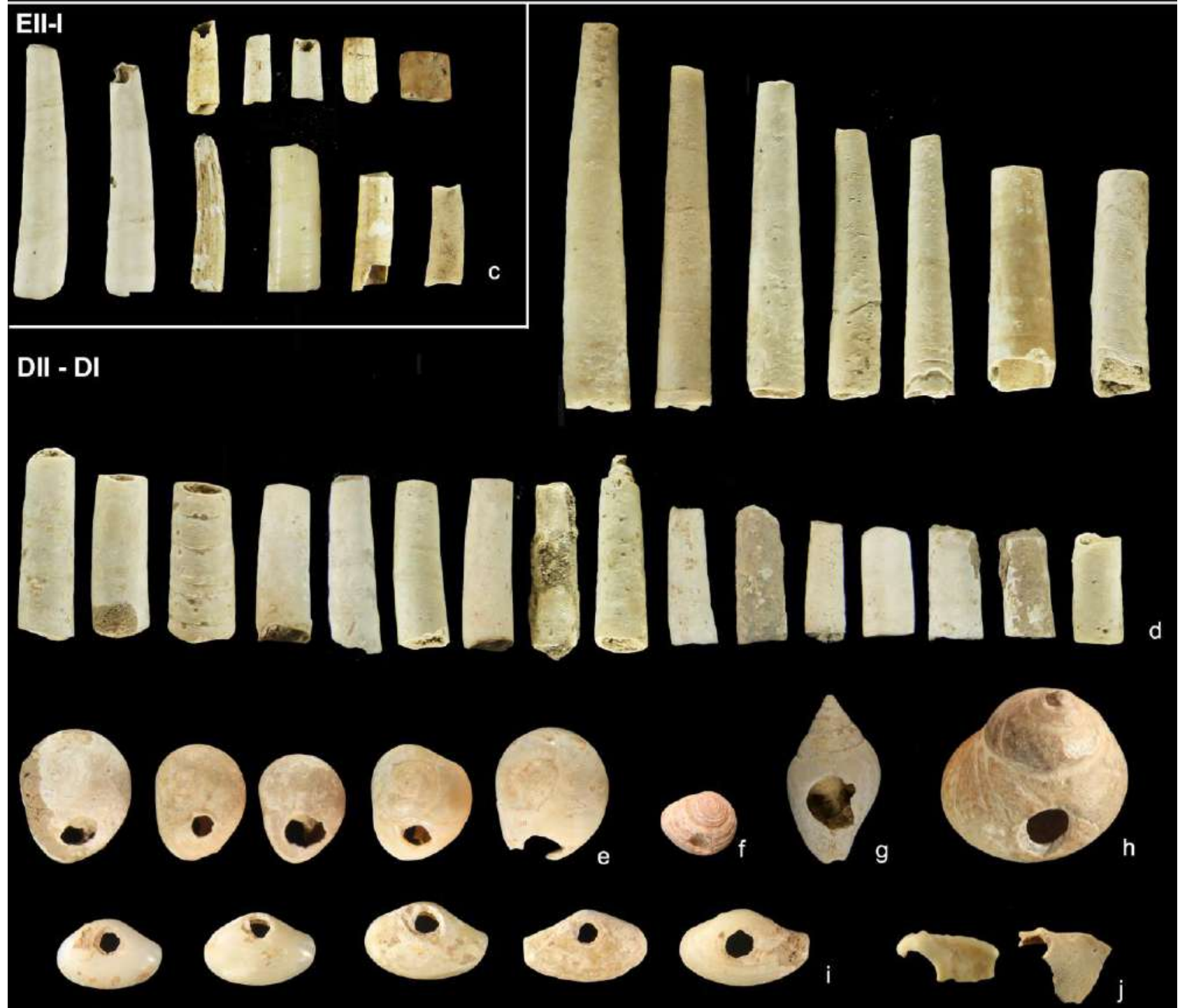

Fig. 2 Selection of shells from Grotta del Cavallo. a Antalis sp. b Tritia neritea. c Antalis sp. d

195 Antalis sp. e Tritia neritea. f Homalopoma sanguineum. g Columbella rustica. h Phorcus turbinatus. i Lembulus pella. J Glycymeris sp. 


\section{Methods} The present research mostly focuses on tusk shells due to their abundance across all layers. Their bad state of preservation, however, required the design of experimental and quantitative analyses to: a) understand whether these shells were collected from fossiliferous deposits rather than from thanatocoenoses (namely 'gathered on the beach); b) ascertain the presence and the effects of anthropogenic breakage and post-depositional processes; c) analyse non-macroscopic morphological change over time.

\subsection{Micropalaeontological and isotope analysis}

The micropalaentological content of several samples of sediment contained in the tusks from Grotta del Cavallo and in the Uluzzian layers of the cave was examined to establish if the shells were collected from nearby sedimentary outcrops or from beach deposits contemporaneous to the Uluzzian activity at the site. The material was examined through classic micropalaentological techniques, which include the preparation of washed samples for the analysis of microfossils and of smear slides for calcareous nannofossils, as well as observation under a microscope (SI appendix, Section II).

In situ trace element analysis was carried out by means of LA-ICP-MS on eight samples of tusk specimens from layers E and D of Grotta del Cavallo to test their diagenetic preservation, and ${ }^{87} \mathrm{Sr} /{ }^{86} \mathrm{Sr}$ ratio was analyzed by MC-ICP-MS to test the non-fossil origin of the archaeological samples (see Lugli et al. 2017) (SI appendix, Section III). Elemental and isotope analyses were conducted at the Centro Interdipartimentale Grandi Strumenti of the University of Modena and Reggio Emilia.

\subsection{Morphological analysis}


223 All the archeological tusk shells were measured (length, maximum and minimum diameters) in

224 accordance with normalized zoological parameters: the apex of the shell is anatomically dorsal, the

225 large aperture is ventral and anterior, and the concave side is anatomically dorsal (Shimek and

226 Steiner 1997).

227 The archeological and experimental tusk shells were classified according to the type of apical and 228 basal fractures. Seven different types of fractures were described (Fig. 3 and Fig. S5):

229 a)Rectilinear: regular and straight fracture, perpendicular to the longest axis of the shell;

230 b)Oblique: regular and straight fracture, oblique to the longest axis of the shell;

231 c)Symmetric-irregular: uneven fracture forming a symmetric profile;

232 d)Asymmetric-irregular: uneven fracture;

233 e)Flute-mouth: uneven fracture taking the shape of a flute mouth;

234 f)Notch: fracture forming a notch;

235 g)Rectangular notch. 

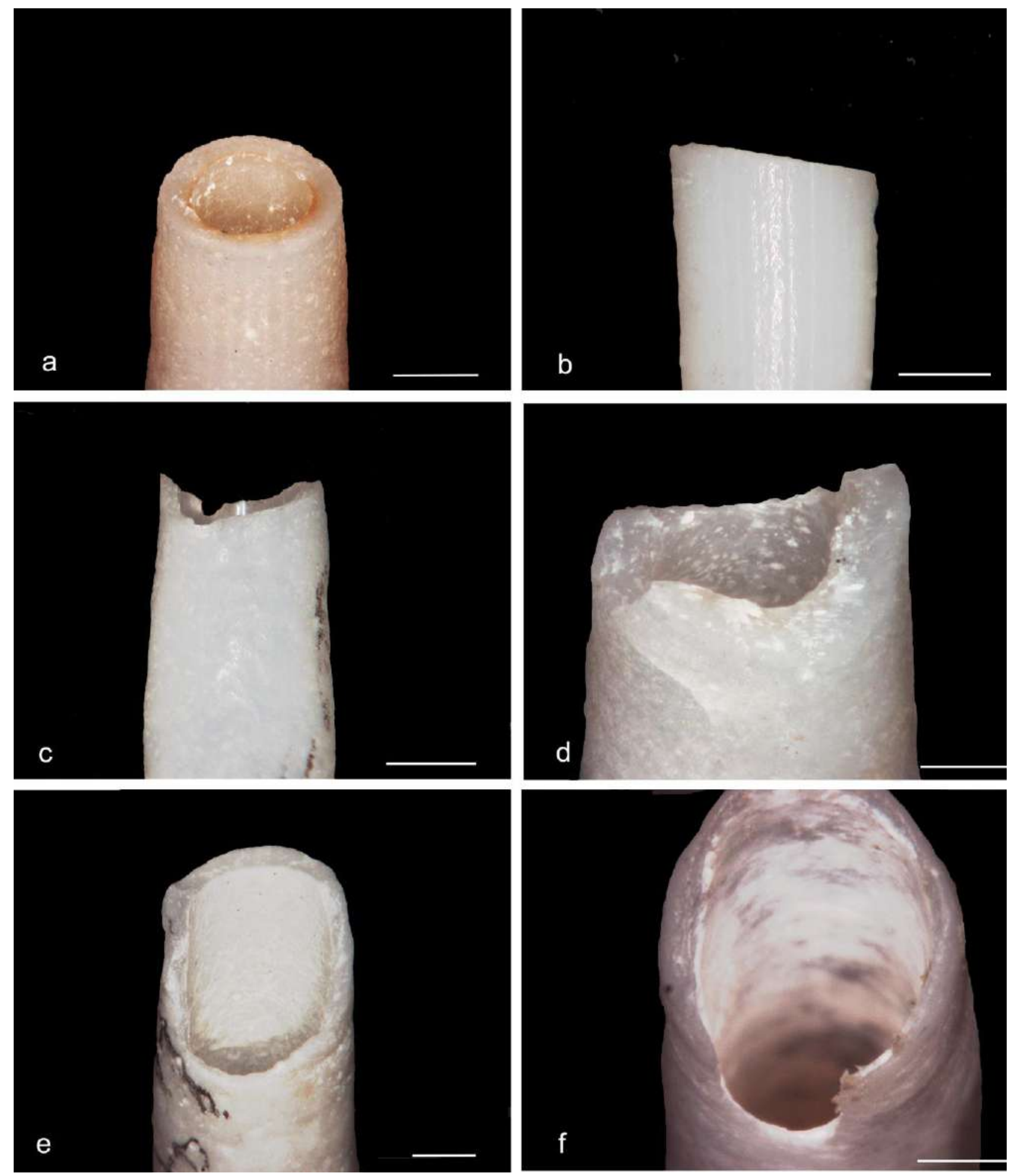

237 Fig. 3 Type of fractures. Classification according to the type of fracture on the experimental

238 material: rectilinear (a), oblique (b), symmetric irregular (c), asymmetric irregular (d), flute-mouth

239 (e), and notch (f). The bar is $1 \mathrm{~mm}$ 
The degree of the fracture's invasiveness and of the discontinuity of the fractured edge were also described. Rectilinear and oblique fractures, which usually have a straight edge, are degree 0 . Jagged edges have a degree value included between 1 and 3, according to invasiveness of the alteration (Fig. 4).

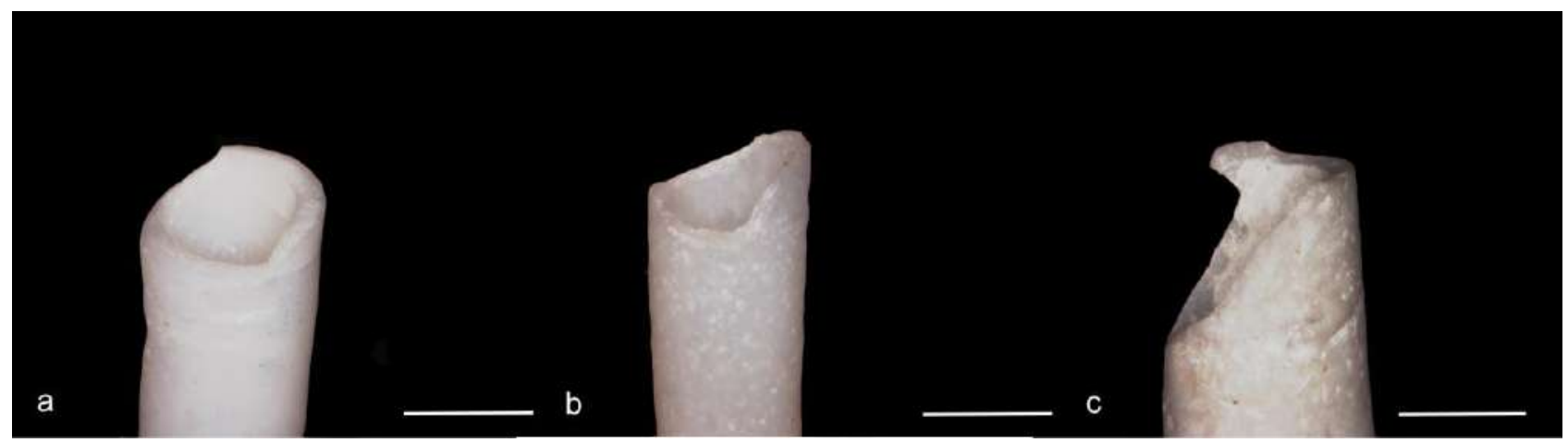

Fig. 4 Fracture degrees. Flute-mouth fracture with degree 1 (a). Flute-mouth fracture with degree 2 (b). Flute-mouth fracture with degree 3 (c). The bar is $2 \mathrm{~mm}$

Specimens were classified according to their remnant portion (entire, apical, central and basal).

Given the general bad preservation of the archaeological shells, this classification is not based on zoological parameters. We consider entire or nearly entire the specimens where all the morphological features can be recognized. The apical (or distal) elements are those in which the posterior end is recognizable. Central (or mesial) portions are usually considered those elements showing scarce difference between maximum and minimum diameter. In the basal (or proximal) elements the base is present.

The possibility that a thread could go through the apical hole was considered as a critical discriminant factor. In this case, apical hole refers to the actual empty space within the shell, and may or may not coincide with the minimum diameter. A minimum threshold of $0.5 \mathrm{~mm}$ was established for this condition to be met, considering that sturdy horsehairs, the smallest suitable strings documented in ethnographic studies (Orchard 1929), present with diameters ranging from 0.08 to $0.4 \mathrm{~mm}$ (Craveri 1931). Of course, other materials, such as vegetal fibers or sinews, cannot be excluded as potential strings for suspension. 


\subsection{Experimental tests}

Experimental tests for shell beads production and post-depositional damage was carried out only for tusk shells, due to their relevance among the whole assemblage and to the difficulty in evaluating the origin of the fracturing on this kind of shell.

The experimental program involved the gathering of current specimens (mostly Antalis vulgaris) in the surroundings of Grotta del Cavallo, their breaking by bending, sawing, crushing (direct percussion) and trampling (for further details see SI Appendix, Section IV). The experimental shells were measured and classified according to the same parameters used for the archaeological ones, before and after each experimental test.

Possible technological attributes of gastropods and bivalves were instead evaluated by comparison with literature data and available reference collections (Taborin 1993; Benghiat et al. 2009; Stiner et al. 2013; Vanhaeren et al. 2013; Tátá et al. 2014).

\subsection{Exploratory data analysis}

Significant differences in unique variables such as length, minimum diameter, and maximum diameter across layers were assessed through non-parametric tests due to small sample size and to the presence of violations of the assumptions of parametric tests. More specifically, two-tailed Mann-Whitney U test for independent study design was performed when only two groups were compared, while Kruskal-Wallis test was used when more than two groups were to be compared against each other. Associations between pairs of categorical variables were explored on contingency tables via Correspondence Analysis using the function ca of the package ca (Nenadic and Greenacre 2007) and through Pearson's Chi-square test for independence. All analyses were run in $\mathrm{R}$ version 3.4.4 (R Core Team 2018).

\subsection{Diversity and similarity}


Intra-layer diversity was measured through Gini-Simpson index of diversity and its numbers equivalent (i.e. the exponential of Gini-Simpson index, following Jost 2006 and 2007 based on the relative frequency of proximal fracture types, distal fracture types, and remnant portions obtained for each layer. Results were obtained using respectively the functions $\mathrm{H}$ and $\mathrm{d}$ contained in the package vegetarian (with order of diversity q=2; Charney and Record, 2012). Similarity between layers was measured through Morisita-Horn index of overlap using the function sim.table of the package vegetarian (with order of diversity $q=2$ ). Clustering of layers was obtained using hierarchical clustering with Ward's clustering criterion (Murtagh and Legendre 2014), i.e. dissimilarities were squared before cluster updating. All analyses were run in R version 3.4.4.

\section{3,6 Taphonomic analysis}

The taphonomic study of the malacological assemblage was performed on the NISP and it focused on three main kinds of alterations: pre-depositional alterations (e.g. marine abrasion, predation by other molluscs and bioerosion); intentional/unintentional anthropogenic alterations (e.g. thermic alterations, ochre traces and human modifications due to consumption or ornamental purpose); and post-depositional transformations (e.g. fragmentations and decalcification).

\subsection{Use-wear analysis}

The shells were analyzed by means of a Hirox KH 7700 3D digital microscope (Arrighi and Borgia 2009) using two different optics: a MX-G 5040Z zoom lens equipped with an AD-5040 Lows objective lens (20-50x) and a coaxial vertical lighting MXG-10C zoom lens and an OL-140II objective lens (140-560x). The analytical criteria (surface polishing, rounding, faceting) for the functional interpretation of the ornaments build upon previous analyses of prehistoric shells described in literature (e.g. Taborin 1993; Vanhaeren and d'Errico 2001; Bonnardin 2007).

\section{Results}


The shell assemblage from Grotta del Cavallo exhibits traces of decalcification (Table 3), in particular in the case of tusk shells. Among the latter, some specimens exhibit partially exfoliated surfaces that probably facilitated post-depositional fragmentation. Sea wash is also documented.

Only a few specimens are affected by alterations due to thermic effects, predator activity or reducing conditions in soil.

\begin{tabular}{|c|c|c|c|c|c|c|c|c|}
\hline $\begin{array}{c}\text { Layers/ } \\
\text { Spit }\end{array}$ & Classes & NISP & Sea washed & Boring sponge & Predators & Burned & Decalc. & Post-dep. cracks \\
\hline \multirow{3}{*}{ E III } & Gastr. & 33 & 25 & - & 1 & 1 & 28 & 14 \\
\hline & Biv. & 7 & 7 & - & - & - & 6 & 5 \\
\hline & Scap. & 67 & 7 & - & - & - & 37 & 3 \\
\hline \multirow{3}{*}{ E II-I } & Gastr. & 1 & - & - & - & - & 1 & 1 \\
\hline & Biv. & 1 & 1 & - & - & - & 1 & - \\
\hline & Scap. & 18 & - & - & - & - & 17 & 2 \\
\hline \multirow{3}{*}{ E-D } & Gastr. & 1 & 1 & - & - & - & 1 & - \\
\hline & Biv. & 1 & 1 & - & - & - & 1 & 1 \\
\hline & Scap. & 17 & - & - & 1 & - & 16 & - \\
\hline \multirow{3}{*}{ D II } & Gastr. & 10 & 10 & - & - & - & 6 & 1 \\
\hline & Biv. & 2 & 2 & - & - & - & 2 & 2 \\
\hline & Scap. & 87 & - & - & - & $1 ?$ & 79 & 3 \\
\hline \multirow{3}{*}{ DI } & Gastr. & 42 & 37 & 1 & 6 & 5 & 19 & 12 \\
\hline & Biv. & 45 & 31 & - & 10 & - & 26 & 17 \\
\hline & Scap. & 87 & 5 & - & - & - & 85 & - \\
\hline D whole & Gastr. & 13 & 11 & - & - & - & 9 & 7 \\
\hline
\end{tabular}




\begin{tabular}{|c|c|c|c|c|c|c|c|c|}
\hline & Biv. & 2 & 2 & 1 & - & - & 2 & 1 \\
\cline { 2 - 8 } & Scap. & 87 & 1 & - & 2 & - & 73 & 1 \\
\hline $\begin{array}{c}\text { Total } \\
\%\end{array}$ & - & 521 & $27.1 \%$ & $0.4 \%$ & $3.6 \%$ & $1.2 \%$ & $78.5 \%$ & $13.4 \%$ \\
\hline Total & & 521 & 141 & 2 & 20 & 7 & 409 & 70 \\
\hline
\end{tabular}

Table 3 Taphonomy of the malacological assemblage from Grotta del Cavallo. Anthropic traces are not included in this table, as they are discussed in the following chapters

\subsection{Scaphopods}

\subsubsection{Fossil and non-fossil origin of the archaeological specimens.}

Since Fissidentalium rectum is an extinct species, this specimen was probably collected at a

fossiliferous Pleistocene formation cropping in the Salento region (Largiolli et al. 1969).

Both micropaleontological analyses (SI Appendix, Section II) carried out on the sediment preserved the other taxa.

\subsubsection{Experimental study}

Manufacturing was experimentally tested on complete and almost complete specimens collected on the present-day beach in the surroundings of Grotta del Cavallo. Naturally broken specimens usually lack the apical portion. Fractures are frequently asymmetric-irregular ( 60\%) (see paragraph Methods and the SI Appendix, Section IV for description of the methodology applied). Rectilinear ( 24\%) and oblique ( $8 \%)$ fractures are less frequent. Many elements have their natural basis preserved. The fracturing degree is predominantly $1(\sim 46 \%)$ and, to a lesser extent, $2(\sim 24 \%)$. 
irregular fractures and crushing ( $\sim 60 \%)$. Unlike other actions, sawing can produce a tiny rectangular notch due to the pressure exerted on the starting point.

Notch fractures, which can be considered lesser developed flute-mouth fractures, cannot be clearly related to a specific bead making technique. These kinds of fractures rarely occur, although their frequency is a bit higher in crushing tests. Vanhaeren and d'Errico (2001) suggest that notch and flute-mouth fractures originate when a needle is used for stringing a thread into a shell. Comparable notch fractures, however, were obtained from our experimental trampling tests and from some explorative suspension tests when one tusk was inserted into the other, as also observed in other research (Álvarez Fernández 2006).

The occurrence of clear cut-marks on the shells is consistently associated with sawing. Bending is mostly related to fractures of degree $0(85 \%)$ and to a lesser extent degree $1(\sim 14 \%)$, sawing almost exclusively to degree $0(\sim 46 \%)$ and $1(\sim 50 \%)$, whereas the effect of crushing is more variable, including degrees $1(\sim 36 \%), 2(50 \%)$ and $3(3 \%)$.

Experimental trampling did not produce substantial evidence of breakage, although it generally results in a more conspicuous presence of chipping at the base of the shell. Fractures associated with trampling are mostly asymmetric-irregular and to a lesser extent flute-mouth and notch usually with degree 2 or 3.

\subsubsection{Morphological and use-wear analysis}

Scaphopods are the most recorded class in all the Uluzzian layers of Grotta del Cavallo. When identified at the species level, they are Antalis dentalis/inaequicostata and Antalis vulgaris (Table 1). Noteworthy is the presence of a single fossil specimen, probable Fissidentalium rectum in the entire macro-layer D.

Central and apical portions are the most common ones in all the layers (SI Appendix, Section VI Table S14). In the uppermost layers (D), short apical portions are particularly abundant (32 out of 261), usually truncated with rectilinear fractures at their base (Fig. 5). This evidence suggests the 
systematic removal of the shell apical portions by flexing, in order to obtain segments with a diameter as wide as possible to allow the passage of the string. For this reason, these short apical fragments could be interpreted as waste products.

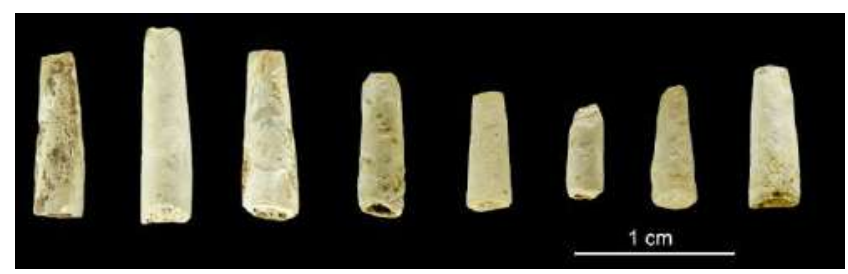

Fig. 5 Waste products. Small apical portions interpreted as waste products

Entire or almost entire specimens are considerably less frequent (SI Appendix, Section VI Table S14). Among these, specimens preserving the apical portions (tot $=91 ; \mathrm{nEIII}=20, \mathrm{nEII}-\mathrm{I}=5, \mathrm{nD}=66$ ) are not suitable for suspension, since their apical holes are too narrow to be stringed.

Rectilinear fractures, followed by irregular asymmetric ones, are the dominant types in all layers (Table 4, SI Appendix, Section VI Table S15-16). In layer EII-I there is a slight predominance of flute-mouth fracture ( $25 \%)$ and rectilinear fracture (25\%) compared to and asymmetric irregular ones ( 16\%; SI Appendix, Section VI Tables S15 and S16; Fig S4). Rectangular notch fractures related to sawing are attested on 1 specimen from layer EII-I and on 2 specimens respectively from DII and D whole (SI Appendix, Section VI Fig. S5). None of these shells exhibit cut-marks.

Scratches comparable to those experimentally produced by cutting with a flint tool (SI Appendix, Section VI Fig. S5 and Fig 6) are recorded only on one tusk (layer DII), which displays rectilinear fractures at both ends and some sort of marks overlapping with the basal one.

\begin{tabular}{|c|l|l|l|l|l|l|l|l|l|}
\hline $\begin{array}{c}\text { Layer/ } \\
\text { Spit }\end{array}$ & Entire & Rectilinear & Oblique & $\begin{array}{l}\text { Asymmetric- } \\
\text { irregular }\end{array}$ & $\begin{array}{l}\text { Symmetric- } \\
\text { irregular }\end{array}$ & $\begin{array}{l}\text { Flute- } \\
\text { mouth }\end{array}$ & Notch & $\begin{array}{l}\text { Rect. } \\
\text { notch }\end{array}$ & Unid. \\
\hline EIII & $12.6 \%$ & $38.8 \%$ & $6.7 \%$ & $23.1 \%$ & $7.4 \%$ & $2.9 \%$ & $8.2 \%$ & $0 \%$ & $0 \%$ \\
& $(17)$ & $(52)$ & $(9)$ & $(31)$ & $(10)$ & $(4)$ & $(11)$ & $(0)$ & $(0)$ \\
\hline
\end{tabular}




\begin{tabular}{|c|c|c|c|c|c|c|c|c|c|}
\hline EII-I & $\begin{array}{l}8.3 \% \\
(3)\end{array}$ & $\begin{array}{l}25 \% \\
(9)\end{array}$ & $\begin{array}{l}5.5 \% \\
\text { (2) }\end{array}$ & $\begin{array}{l}16.6 \% \\
(6)\end{array}$ & $\begin{array}{l}8.3 \% \\
(3)\end{array}$ & $\begin{array}{l}25 \% \\
(9)\end{array}$ & $\begin{array}{l}8.3 \% \\
\text { (3) }\end{array}$ & $\begin{array}{l}2.7 \% \\
\text { (1) }\end{array}$ & $\begin{array}{l}0 \% \\
(0)\end{array}$ \\
\hline E-D & $\begin{array}{l}5.8 \% \\
(2)\end{array}$ & $\begin{array}{l}32.3 \% \\
(11)\end{array}$ & $\begin{array}{l}5.8 \% \\
\text { (2) }\end{array}$ & $\begin{array}{l}23.5 \% \\
(8)\end{array}$ & $\begin{array}{l}0 \% \\
(0)\end{array}$ & $\begin{array}{l}11.7 \% \\
(4)\end{array}$ & $\begin{array}{l}17.6 \% \\
(6)\end{array}$ & $\begin{array}{l}0 \% \\
(0)\end{array}$ & $\begin{array}{l}2.6 \% \\
\text { (1) }\end{array}$ \\
\hline DII & $\begin{array}{l}12.6 \% \\
(22)\end{array}$ & $\begin{array}{l}37.3 \% \\
(65)\end{array}$ & $\begin{array}{l}5.1 \% \\
(9)\end{array}$ & $\begin{array}{l}24.7 \% \\
(43)\end{array}$ & $\begin{array}{l}2.8 \% \\
(5)\end{array}$ & $\begin{array}{l}7.4 \% \\
(13)\end{array}$ & $\begin{array}{l}8 \% \\
(14)\end{array}$ & $\begin{array}{l}0,5 \% \\
(1)\end{array}$ & $\begin{array}{l}1.1 \% \\
(2)\end{array}$ \\
\hline DI & $\begin{array}{l}13.7 \% \\
(24)\end{array}$ & $\begin{array}{l}40.8 \% \\
(71)\end{array}$ & $\begin{array}{l}4 \% \\
(7)\end{array}$ & $\begin{array}{l}29.8 \% \\
(52)\end{array}$ & $\begin{array}{l}1.1 \% \\
(2)\end{array}$ & $\begin{array}{l}5.7 \% \\
(10)\end{array}$ & $\begin{array}{l}2.8 \% \\
(5)\end{array}$ & $\begin{array}{l}0 \% \\
(0)\end{array}$ & $\begin{array}{l}1.7 \% \\
(3)\end{array}$ \\
\hline $\begin{array}{l}\mathrm{D} \\
\text { whole }\end{array}$ & $\begin{array}{l}10.9 \% \\
(19)\end{array}$ & $\begin{array}{l}43.1 \% \\
(75)\end{array}$ & $\begin{array}{l}2.8 \% \\
(5)\end{array}$ & $\begin{array}{l}28.7 \% \\
(50)\end{array}$ & $\begin{array}{l}2.2 \% \\
\text { (4) }\end{array}$ & $\begin{array}{l}8 \% \\
(14)\end{array}$ & $\begin{array}{l}2.8 \% \\
\text { (5) }\end{array}$ & $\begin{array}{l}0.5 \% \\
\text { (1) }\end{array}$ & $\begin{array}{l}0.5 \% \\
(1)\end{array}$ \\
\hline
\end{tabular}

387 Table 4 - Frequencies of the fractures identified on tusk shells by layer. Real data are reported in 388 brackets

390 The majority of fractures exhibit degree 0 (50.8\%), and frequency tends to decrease with increasing

391 fracture degree (degree 1=22.8\%; degree 2=19.8\%; degree 3=6.0\%) SI Appendix, Section VI Tables

$392 \mathrm{~S} 17-\mathrm{S} 22)$. A different trend is registered in layer EII-I, where degree 2 is the predominant one. 

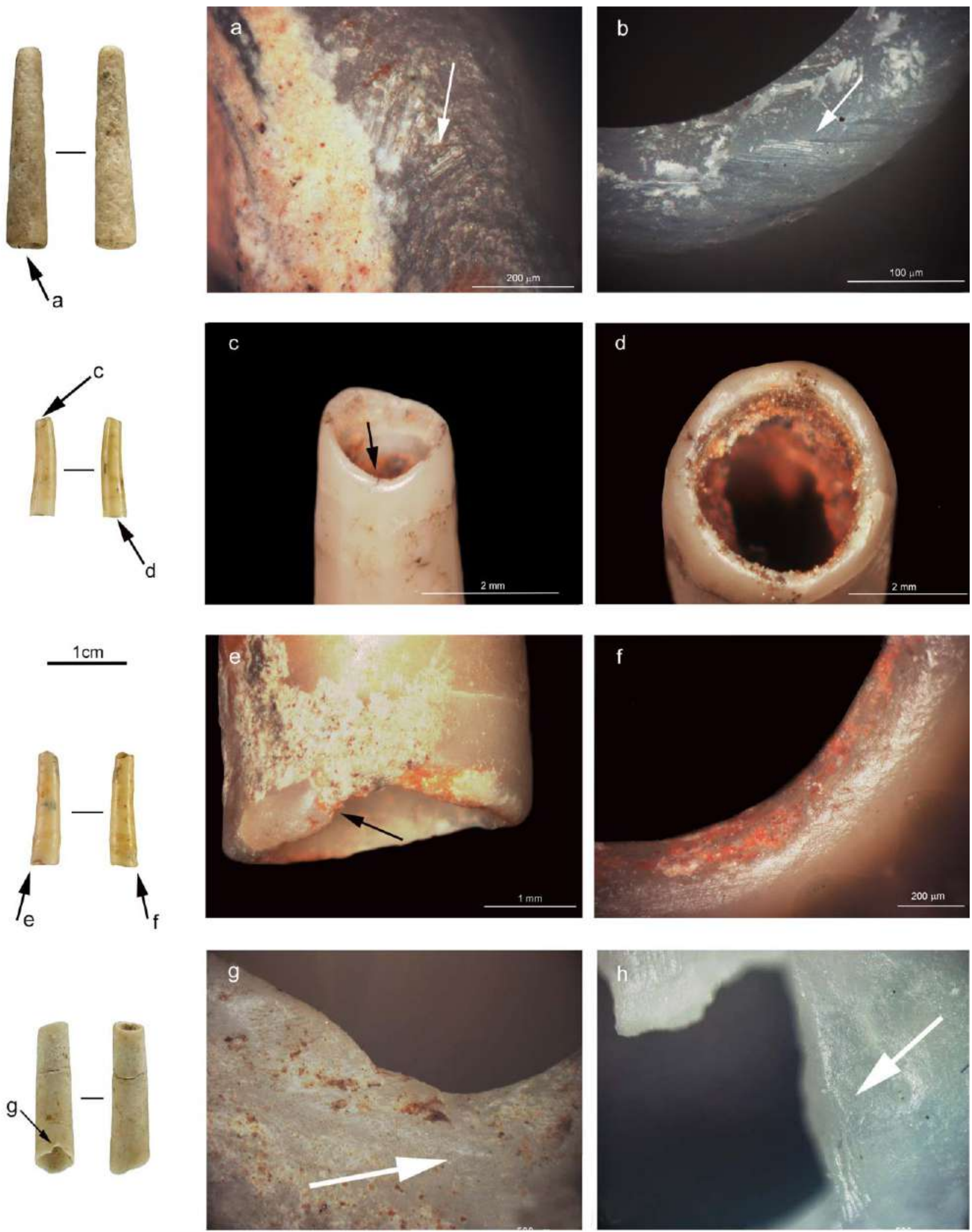

394 Fig. 6 Traces of anthropogenic manipulation. Grotta del Cavallo. Layer DII - tusk shell with cutmarks (a), this kind of marks is very similar to those obtained experimentally by cutting tusk shells with a flint tool (b). Layer EIII— - tusk shell with a notch fracture showing well rounded (c) and 
polished edges (d). Layer EIII - tusk shell showing a notch fracture with flattened (e) and polished areas (f). Layer EIII-weak polishes inside a notch fracture (g) and weak polishes inside a notch fracture produced during suspension experiment with a leather string $(\mathrm{h})$

The retrieval of two shells inserted into each other is documented in three cases (layers EII-I, E-D, and DI). This eventuality can be due either to human intervention or taphonomic causes (Fig. 7).

Intentional insertion of tusk shells into each other, especially for the making of necklaces, is well documented in both archaeological and ethnographic evidence (Ruppert and Bernet 2001;

Dimitrijević 2014). Otherwise, this occurrence was also observed during the gathering of presentday tusks used for experimental tests, even if in the whole collected sample (1908 tusks) only one case of insertion was reported. Since the tusks retrieved in layer DI could be easily separated, the parts of the surface originally located inside the external tusk were analyzed. This portion appears considerably better preserved and presents some polished areas, while the exposed surface exhibits the usual altered appearance (Fig. 7).
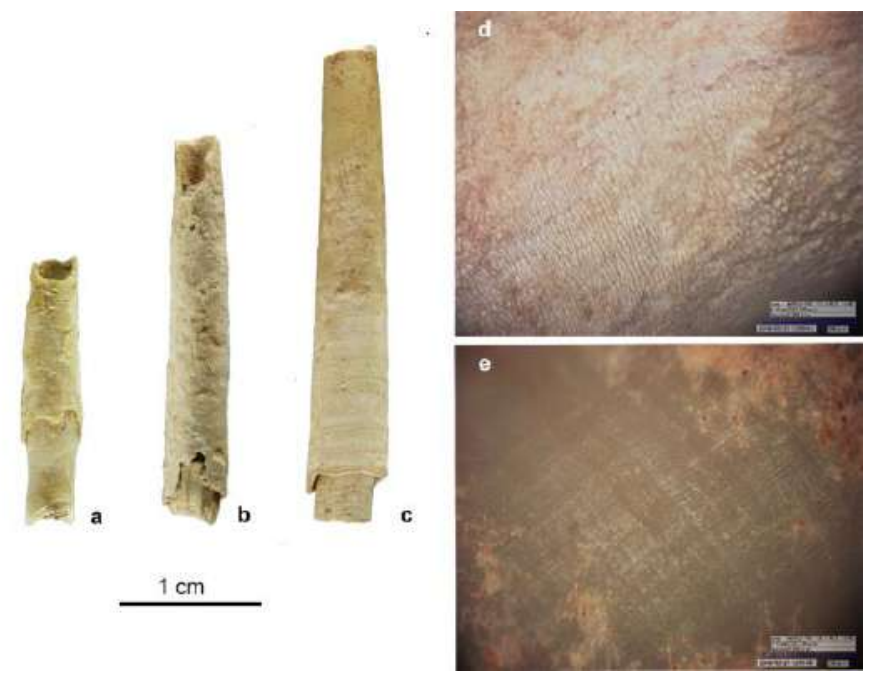

Fig. 7 Tusk shells inserted one into another from Grotta del Cavallo. Tusk shells inserted one into another from layer EII-I (a), spit E-D (b), and layer DII (c), while the external surface of the tusks looks weathered (d), and the inner, protected trait shows its original aspect (e) 
Consequently, the insertion can be considered intentional and not due to post-depositional

processes. Unexpectedly, the same pattern was detectable on the surface of the external shell. In this case two scenarios can be envisaged:

1.The external shell was in its turn inserted into another shell, which is now lost.

2.This differential surface preservation could be attributed to post-depositional phenomena acting with different intensity on the two shells (partial burial for some time?)

According to the first hypothesis, we can imagine an adornment object composed of several tusks, inserted into each other, as largely reported in archaeological and ethnographic contexts (Ruppert and Bernet 2001; Dimitrijević 2014).

A number of tusks (11) from layer EIII are coated with red pigment, usually on the whole outer and inner surfaces (Fig 8). Other items (14) preserve only a few residues of red coloring. They were all retrieved in two adjacent square meters of the excavation grid (SI Appendix, Section VI Fig. S1) and 20 out of 25 ochered items are suitable for suspension, possibly suggesting that the shells were colored in an ornamental perspective.

Traces of red pigment were also recovered on a specimen from layer EII-I. The coloring substance is distributed inside the tusk and spreads longitudinally (Fig 8).
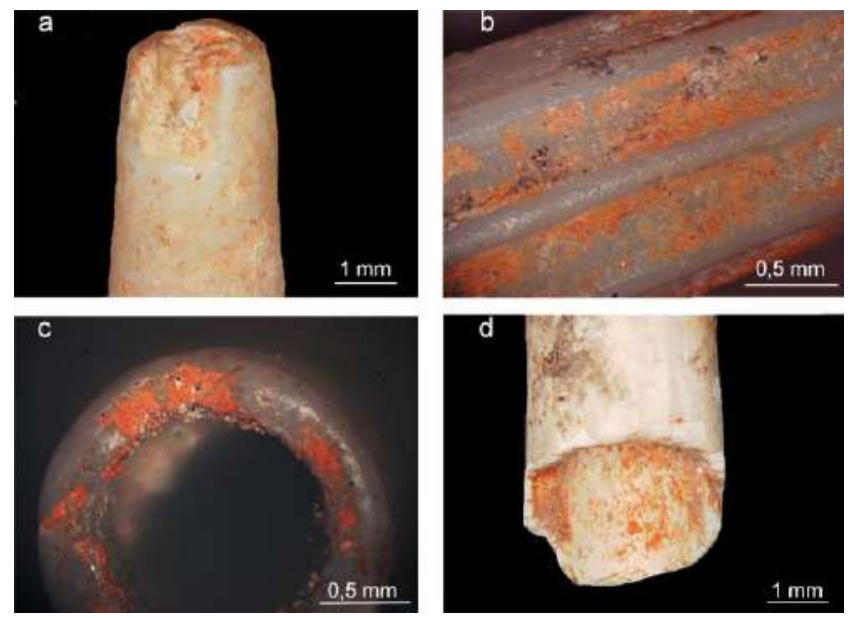

Fig. 8 Ochered shells from Grotta del Cavallo. Layer EIII- ocher associated to a notch fracture (a). Ocher and black residues on the external surface of a specimen (b). Ocher on the apical end of a 
tusk. The edge is rounded and polished (c). Layer EII-I—ocher located inside the shell and longitudinally spread (d)

Usually, scaphopods are not well-preserved due to decalcification. Only in layer EIII a good number (30) of tusks exhibits well-preserved surfaces. About half of them (18) show weak traces of polishing on the outer surface of one or both ends (Fig. 6), often clustered on a limited portion of the rim (Fig 6). Such traces appear more frequently in central (9) and apical (7) portions, and to a lesser extent in basal ones (1) and almost complete (1) shells. Polishing traces are associated with rectilinear, asymmetric, symmetric irregular, and notch fractures.

In the uppermost layers the state of preservation of tusks did not allow for a reliable evaluation of suspension traces. Nevertheless, when the pristine surface of the shell is preserved, slightly rounded edges on one or both extremities can be observed, although it is difficult to identify actual patterns and therefore to discriminate between usage (suspension) and post-depositional processes. Specimens displaying such traces are 3 in layer EII-I, 3 in split E-D, and 25 in unit D. It usually consists of central portions mainly associated with rectilinear or notch fractures.

\subsubsection{Analysis of variability over time}

Quantitative analyses were run on a controlled subset $(n=255)$ obtained excluding observations uncovered in the E-D split and shells generically attributed either to layer DI or DII. Records with missing information were also not considered $(n=4)$. In this case, sampled shells are almost equally distributed across layers with the exception of EII-I (nEIII=67, nEII-I=17, nDII=87, nDI=84).

Results show that shell minimum and maximum diameter are significantly wider in Antalis $s p$. than in Antalis vulgaris and Antalis dentalis/inaequicostata (SI Appendix, Section VII Tables S23, S26 and S27). At the same time, maximum diameter increases over time for all the examined portions including apical ones (SI Appendix, Section VII Fig. S6; Tables S30-32), and such an increase is mirrored by significant increase in the minimum diameter of medial pieces (SI Appendix, Section 
VII Fig. S6; Table S33). Length of entire shells also increases over time (SI Appendix, Section VII Tables S28 and S35, Fig. S6). However, no difference in length in any layers between likely suspended apical pieces and pieces that are less likely to have been used in suspension was recorded (SI Appendix, Section VII Table S34).

The distribution of both distal and proximal fracture types significantly differs across layers (Tables S24-25 and S38-40). More in detail, rectilinear and irregular asymmetric fractures are the most frequent types among proximal fractures, and their presence tends to increase over time (SI Appendix, Section VII Table S36). Layer EII-I is associated with "notch", "rectilinear cut", and "flute-mouth" fractures and is segregated from all other layers in multivariate analyses.

Correspondence Analysis also suggests a shift over time from irregular/symmetric and oblique fractures to irregular/asymmetric and rectilinear fractures in both distal and proximal fractures.

The distribution of remnant portions and that of potentially suspended pieces does not significantly differ from one layer to the other (SI Appendix, Section VII Table S35 and Tables S38-39). The distribution of distal fractures is significantly associated with the possibility of being worn in suspension in the whole of the stratigraphic sequence (SI Appendix, Section VII Table S41-43). More specifically, rectilinear fractures are more frequent in potentially suspended pieces, while nonsuspended pieces exhibit no distal fractures in any layers with the exception of two instances of rectilinear fracture in layer DI (SI Appendix, Section VII Tables S44-46). The relative proportion of different fracture types visibly changes over time (SI Appendix, Section VII Tables S47-53).

Diversity in proximal and distal fracture types steadily decreases over time, while diversity in remnant portion types tends to increase over time (SI Appendix, Section VII Fig. 9). Frequency seriation (SI Appendix, Section VII Fig. S8) suggests the progressive emergence of irregular asymmetric fractures become more abundant over time while irregular symmetric, notch, oblique, and flute-mouth fractures decrease in both apex and base. Proximal portions and entire shells are the least represented in the assemblage (SI Appendix, Section VII Fig. S8). It is interesting to note that, 

layers.

a

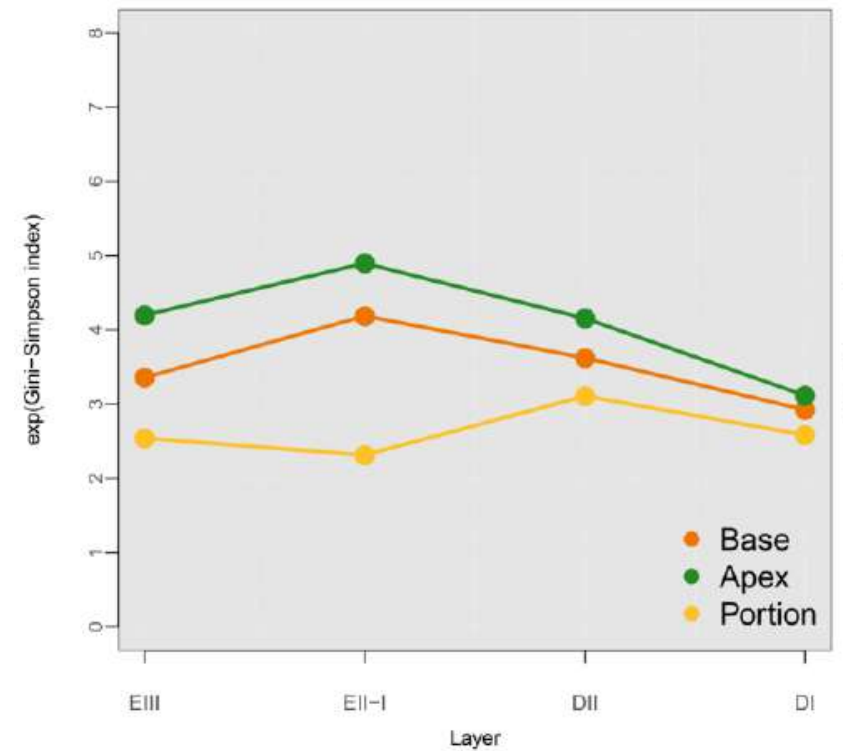

b

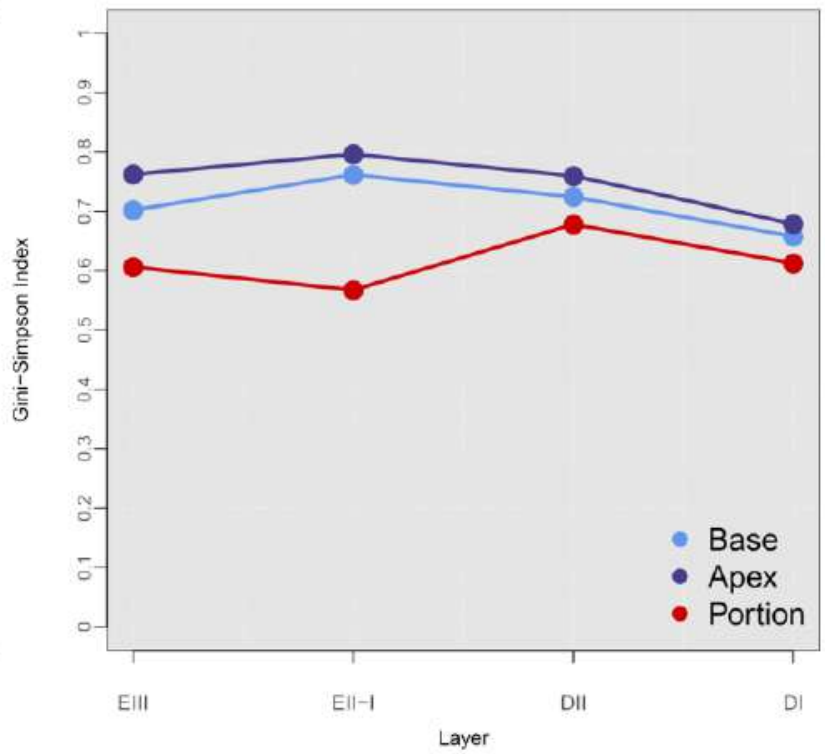

489

490

491

492

493

494

495

496

497

498

499

Fig. 9 Diversity over time graphs representing Gini-Simpson's diversity index (a) and their

equivalent numbers (b; following Jost 2006) across the sequence of examined layers at Grotta del Cavallo

When layers are clustered based on measures of pairwise similarity (SI Appendix, Section VII Table S54; Fig. S9) EII-I always emerges as the outlier.

\subsection{Gastropods and bivalves}

In the archaic Uluzzian layer EIII gastropods and bivalves are scarce $(n=40)$ and affected by high fragmentation $(87.5 \%)$ and decalcification (Table 3).

\begin{tabular}{|c|l|c|c|c|c|c|c|c|}
\hline $\begin{array}{c}\text { Layers/ } \\
\text { Spit }\end{array}$ & \multirow{2}{*}{ Classes } & \multirow{2}{*}{ NISP } & \multicolumn{6}{|c|}{ Anthropogenic processes } \\
\cline { 4 - 9 } & & & ochre & tot_hole & broken & abr_crack & anthropic & anthropized \\
\hline \multirow{2}{*}{ E III } & Gastr. & 33 & - & 2 & - & - & 1 & - \\
\cline { 2 - 9 } & Biv. & 7 & - & - & - & - & - & - \\
\hline
\end{tabular}




\begin{tabular}{|c|l|c|c|c|c|c|c|c|}
\hline \multirow{2}{*}{ E II-I } & Gastr. & 1 & - & 1 & - & 1 & - & - \\
\cline { 2 - 9 } & Biv. & 1 & - & - & - & - & - & - \\
\hline \multirow{2}{*}{ E-D } & Gastr. & 1 & - & - & - & - & - & - \\
\cline { 2 - 10 } & Biv. & 1 & - & - & - & - & - & - \\
\hline \multirow{2}{*}{ D II } & Gastr. & 10 & 1 & 6 & - & - & 6 & - \\
\cline { 2 - 10 } & Biv. & 2 & - & - & - & - & - & - \\
\hline \multirow{2}{*}{ DI } & Gastr. & 42 & 2 & 17 & 1 & 6 & 5 & - \\
\cline { 2 - 10 } & Biv. & 45 & 1 & 12 & 2 & 2 & - & 8 \\
\hline \multirow{2}{*}{$\begin{array}{c}\text { Total } \\
\%\end{array}$} & Gastr. & 13 & 1 & 5 & 3 & 1 & 1 & - \\
\cline { 2 - 10 } & Biv. & 2 & - & 1 & - & 1 & - & - \\
\hline \multirow{2}{*}{ Total } & - & $\mathbf{1 5 8}$ & $\mathbf{3 . 1 \%}$ & $\mathbf{2 7 . 8 4 \%}$ & $\mathbf{3 . 7 \%}$ & $\mathbf{6 . 9 \%}$ & $\mathbf{8 . 2 \%}$ & $\mathbf{5 . 0 \%}$ \\
\hline
\end{tabular}

501 Table 5 Anthropogenic traces on the bivalve and gastropod assemblage by layer

502 Among all uncovered specimens the most outstanding one consists of a complete pierced specimen 503 of Tritia neritea (Table 5 and Fig. 10a). The cross-section exhibits traces of flacking on the outside 504 surface (defined "interior wedging" by Tátá et al. 2014) that are consistent with perforation from 505 the inside of the shell. A notch found on the edge of the shell (Fig. 10a) and the rounded rims of the 506 pierced hole are compatible with repeater contact with a rope used to thread the bead. 

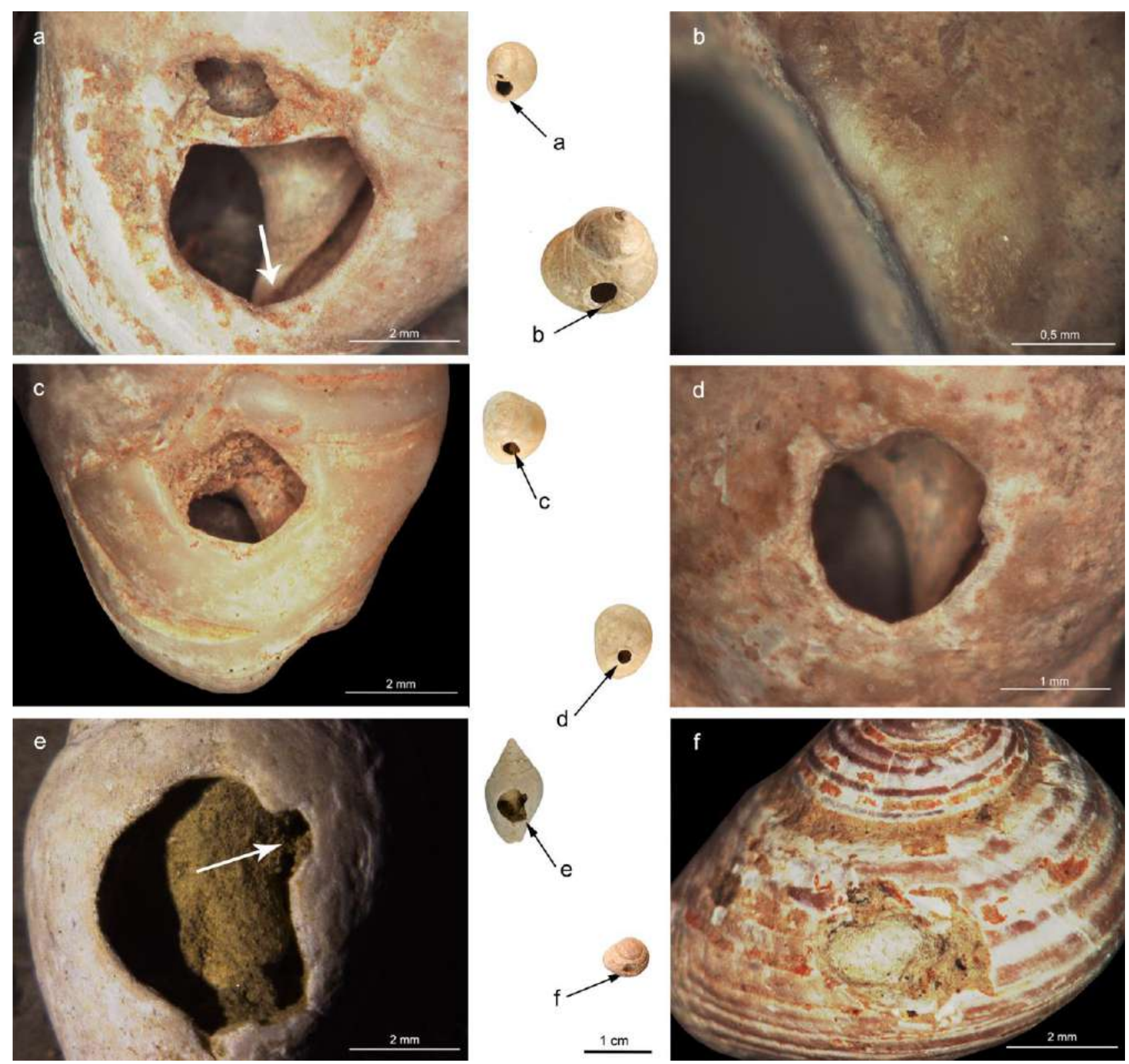

Fig. 10 Technological traces on gastropods from Cavallo. Layer EIII- perforated Tritia neritea showing a notch consistent with suspension (a). Layer DII-close-up of use-wear on the edge of the

510 hole on a perforated Phorcus turbinatus (b). Layer DII—rounded edges on perforated specimens of 511 Tritia neritea (c, d). Layer DI-perforation on a Columbella rustica, showing a notch and rounded 512 edge (e). Layer DI- subcircular hole on a Homalopoma sanguineum (f)

A decalcified fragment of Callista chione, a Naticarius hebraeus covered with concretions and two unidentified fragments are the only shells found in layer EII-I. The three holes identified on the specimen of $N$. hebraeus present with irregular contours and potential recent breakage of the edges, all of which point to post-depositional processes (Fig. 11a). 

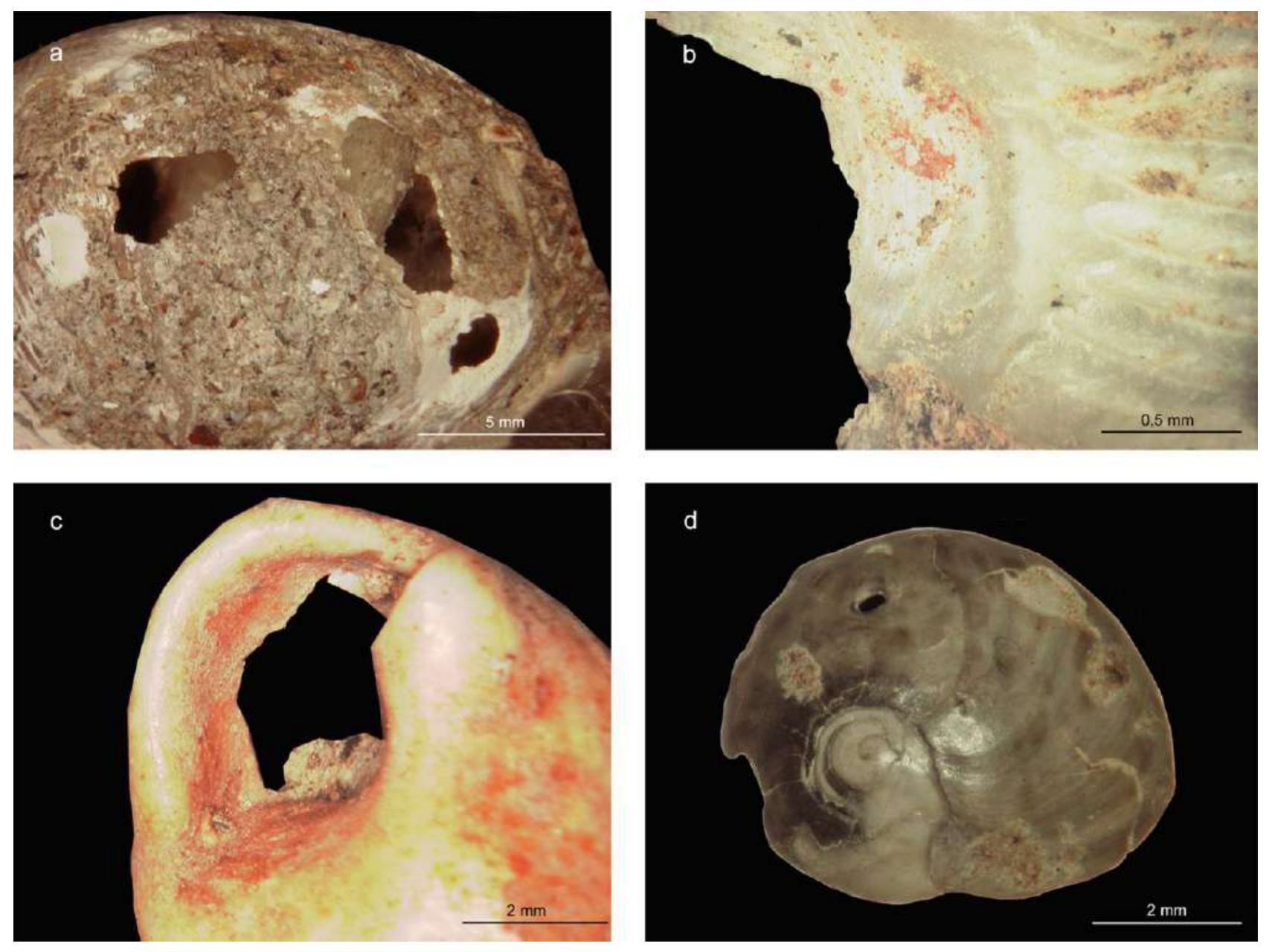

519 Fig. 11 Layer EII-I—postdepositional holes on a Naticarius hebraeus (a). Layer DI—traces of

520 red pigment near the hole of a Lembulus pella (b). Layer DI—residues of red pigment located

521 inside the hole of a Tritia neritea (c). Layer DI- heat cracks on a Tritia neritea (d)

523 Only two identified specimens have been retrieved in the transitional split E-D: a fragment of

524 Spondylus gaederopus and a small shell of Euspira catena. These remains no longer show the

525 periostracum and their sculptural features due to decalcification.

526 Layers DII and I (Upper Uluzzian) stand out for the large number of gastropods and bivalves. In

527 particular Tritia neritea $(\mathrm{n}=31)$ and Homalopoma sanguineum $(\mathrm{n}=11)$ are the most abundant species

528 in the assemblage. The taphonomic study (Table 3) identified traces of beach weathering on $90 \%$ of

529 gastropods and traces of predation by other carnivores on $\sim 9 \%$ of them. These results suggest that 
the vast majority of gastropods were collected dead from beach shores, and they were not taken to the cave to be consumed as food. The most represented species such as T. neritea. H. sanguineum, C. rustica and Ph. turbinatus present with regular sub-circular holes located near the shell aperture. Notches were detected on hole rims, and edges were abraded probably due to use-wear (Fig.10 b-f). The majority of notches are located in the IV (31\%) and I (38\%) quarters (Fig.12), and are consistent with the use of T. neritea as suspended ornaments.

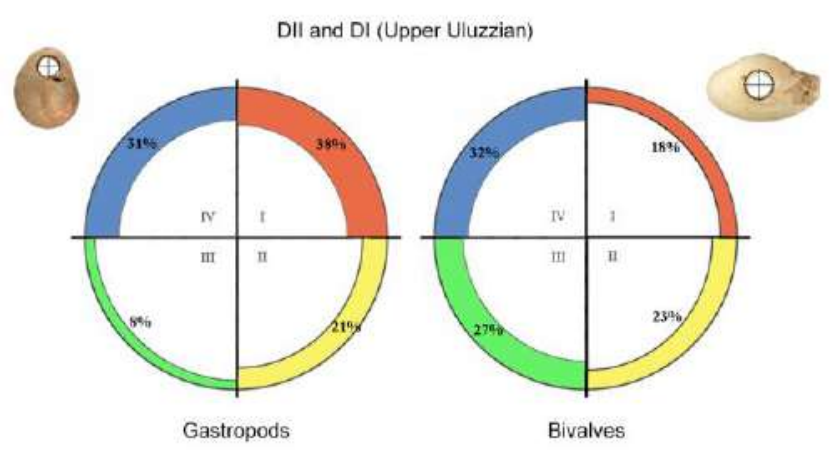

Fig. 12 Graphic representation of the location of notches on edges of pierced shell found at Grotta del Cavallo during the Upper Uluzzian (DII-DI) Ochre was found inside three specimens (Fig. 11b and c), and five gastropods show heat cracks on their external surface (Fig 11d).

Bivalves mostly consist of Mytilis galloprovincialis, Glycymeris sp., and Lembulus pella. The first species is represented by fragments and hinges. Two broken hinges of Glycymeris sp. exhibit partial holes on the umbos although fragmentation makes it impossible to discriminate between anthropic and natural taphonomic processes. Specimens of L. pella consist instead of entire valves. Taphonomic analysis based on all fragments and the small amount of complete specimens support the conclusion that almost $70 \%$ of bivalve remains were abraded by sea waves on the shore. Furthermore, all valves of $L$. pella show perfectly round and bevelled holes, both signs of drilling by mollusc predators. Nevertheless, notches and irregular flaking are once again visible on the edges of drilled holes (Fig. 13a-c), both of which are consistent with use-wear (Fig. 13b-c). These traces, however, are not coherent with drilling perforation operated by other molluscs (Fig.13d). 
The notches are located near the umbo (quarter IV, 32\%) and on the edge above it (quarter III, 27\%)

(Fig.12). We therefore suggest that these naturally pierced shells were deliberately chosen to be used as beads by humans. In addition, some red dusty substance (possibly ochre) was found on the external surface of one of the valves (Fig.11d).
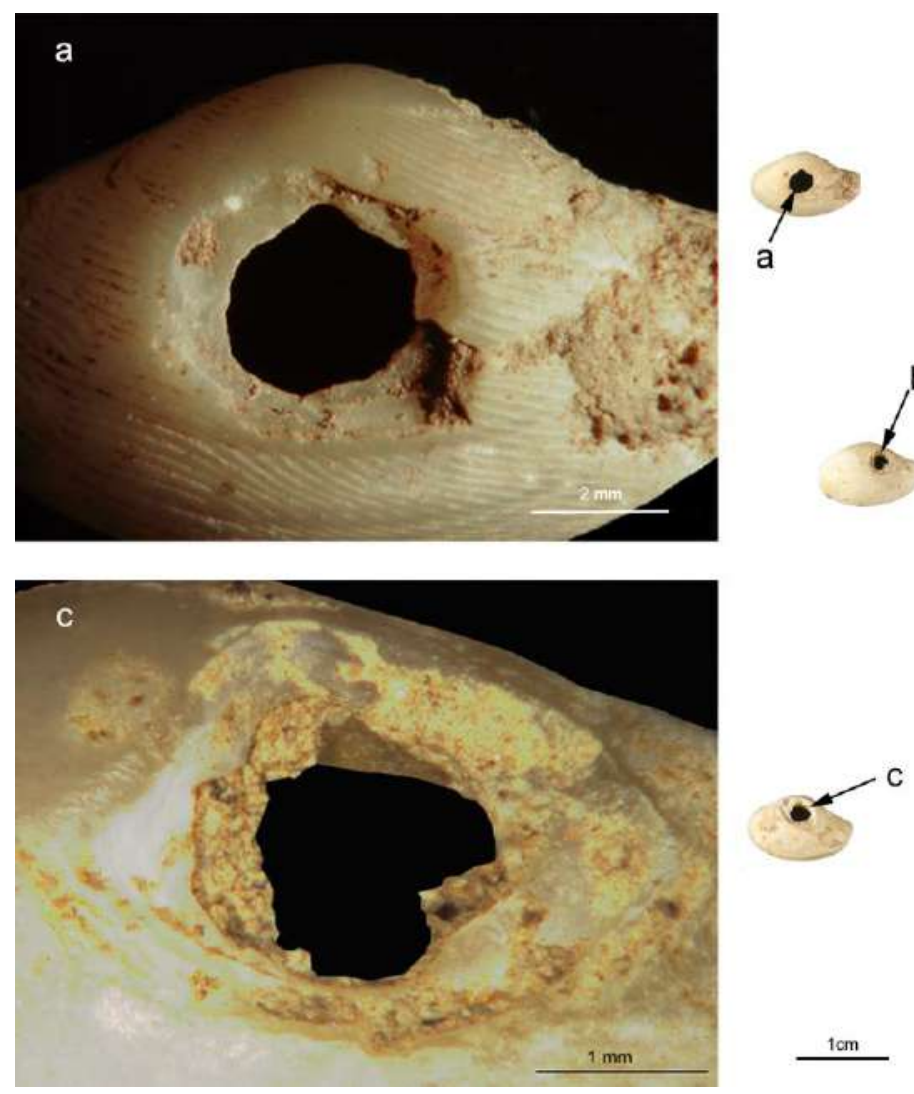
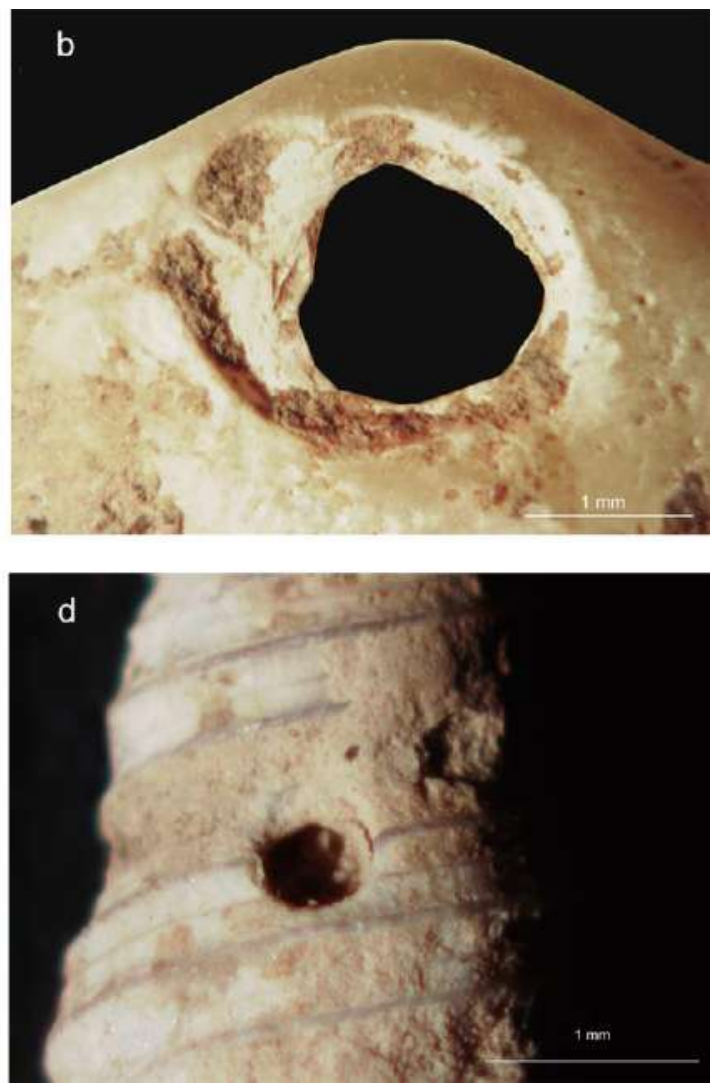

Fig. 13 Layer DI—L. pella with a round drilled hole showing a notch in quarter IV (a). Layer DIL. pella with drilled holes showing notches in quarter IV and irregular flaking (b, c). Layer EIIIhole due to predation on a Turritella sp. (d)

\section{Discussion}

The ornamental shell assemblage of Grotta del Cavallo is mostly characterised by a large amount of scaphopods which are present across the entire archaeological sequence and abound in the uppermost layers, where gastropods and bivalves are also recorded. Among gastropods Tritia neritea is the most frequently recorded species, while Lembulus pella dominants among bivalves.

\subsection{Bead making at Grotta del Cavallo}


As far as tusk shells are concerned, the results of our multidisciplinary study point to an anthropogenic action both in terms of their collection and manufacture. As attested by directly dating results (Benazzi et al. 2011), and micropaleontological and Sr isotope analyses, the archaeological specimens presented here are not fossil shells deriving from sedimentary outcrops located in site surroundings, but rather consist of shells collected from beach shores at the same time as the Uluzzian occupation of Grotta del Cavallo. The distance between Grotta del Cavallo and the coastline was then about $12 \mathrm{~km}$, enough to exclude any possible natural origin for the occurrence of tusk shells inside the cave (Appendix, Section VIII and Fig S10).

These molluscs live in the sandy seabed below the intertidal zone, down to relatively great depths (Appendix, Section IX). Therefore, they were most likely collected by the Uluzzian groups on the beaches of shores that today are submerged. The collection of scaphopods by prehistoric people for feeding purposes is generally rejected, considering their small size and their very low nutritional value (Bar-Yosef Mayer 2008).

Data resulting from our experimental and statistical tests support a human origin also for manufacture, and experimental results reveal a possible association between scaphopod portioning and type of fracture. Nevertheless, we agree with Vanhaeren and d'Errico (2001) and Taborin (1993) that no specific fracture can be univocally associated with anthropogenic action. Although intentionality cannot be definitely proven for any rectilinear fracture uncovered in archaeological assemblages, this kind of fracture is abundant in the dataset from Grotta del Cavallo, while it is considerably rarer among experimental samples generated through trampling or in shells collected on the present-day beaches, as already pointed out by previous research (Vanhaeren and d'Errico 2001). The only traces that surely correlate with human intervention are sawing cut-marks. In the assemblage of Cavallo cut-marks were identified only on one specimen from layer D because of the general bad state of preservation of all shells. In both layers E and D at Cavallo, however, a particular notch-shaped fracture is documented, which, based on our experimental results and on data from the literature (Vanhaeren and d'Errico 2001), can still be related to sawing. The other 
types of fractures (in particular asymmetric and symmetric irregular fractures) are less diagnostic because they can be also produced by trampling and other post-depositional processes. Notch and flute-mouth fractures can also occur during suspension, due to the contact among beads (Álvarez Fernández, 2006). In this light, the presence of red coloring substances on the shells exhibiting flute-mouth and notch fractures becomes more informative. These characteristics are reminiscent of the ochred shell from Riparo Broion, also displaying a notch fracture (Appendix, Section X, Fig. S12).

Results also support change over time in the most represented distal and proximal fracture types. Irregular asymmetric and rectilinear fractures increase their presence over time and become the most represented ones. In earlier phases, notch, oblique, and irregular symmetric fractures are more frequent. Diversity is generally high in the whole of the sequence (especially in distal fractures). Nevertheless, a tendency towards higher homogeneity of fracture types can be ascertained over time (lowest diversity in DI), with a preference for rectilinear ones. This evidence may be also due to a change in manufacturing techniques (i.e. percussion technique in earliest and bending in recent phases respectively) or to different post-depositional processes. Dimensional analysis shows a generalised increase in complete shell size and maximum diameter of all portions over time. This could be due to a change in catchment preference guided by a selective pressure for bigger shells; or it could relate to change in environmental conditions, despite data are still scarce to support this hypothesis. Relations between some environmental factors and morphological variations (e.g. body size) are known for the most common benthic molluscs in the Mediterranean (e.g. Mamouridis et al. 2011; Peharda et al. 2017), but currently are not available for Antalis specimens.

Despite the increase in the size of entire shells over time, length of distal pieces does not change and may reflect a choice aimed to obtain homogeneous beads. Although the level of regularity exhibited by the Magdalenian parure of La Madeleine in France (Vanhaeren and d'Errico 2001) is never reached. In the assemblage found at Cavallo there are also entire tusks that are suitable for suspension, suggesting that this use might have involved beads of different size. The type of tusk 
remnant portions tends to become more diverse over time. Only layer EII-I exhibits a different distribution, displaying a predominance of medial portions consistently associated with a large variety of fracture types (in both apex and base).

Furthermore, the presence of short apical portions in unit D often associated with rectilinear fractures at the base of the apical portion, could suggest a manufacturing process in situ. They seem to illustrate the systematic breakage of the apexes by bending to obtain beads easily and quickly.

As far as gastropods and bivalves are concerned, $13.2 \%$ of the total NISP exhibits traces of anthropic manipulation for ornamental purposes. Nevertheless, shell collection for dietary purpose can be confidently excluded for most gastropods and bivalves, because of their small size and because they were collected dead on beaches, as suggested by taphonomic analysis (Stiner 1999; Vanhaeren and d'Errico 2006; Colonese et al. 2011; Stiner et al. 2013; Stiner 2014; Bosch et al. 2015).

Tritia neritea is the most frequent species among gastropods (37.5\% of which exhibits signs of perforation) followed by Homalopoma sanguineum (18.2\% of which is perforated).

Pierced specimens show a high degree of $\mathrm{s}$ regularity in perforation techniques. Holes are consistently located near the shell aperture, anthropogenic-flaking is always found on the outer surface of the shell, and use-wear abrasion is consistently found on the lips near the aperture. These data are consistent with those observed in our experimental collection, even though further tests are required to better understand the exact method of perforation.

Bivalves seem to be less frequently chosen as adornment objects, evidence of which can be only found in the latest Uluzzian phase (layer DI). This might be due to the great incidence of alimentary species among bivalves, such as Mytilus galloprovincialis, Glycymeris nummaria and Callista chione. Anthropogenic traces can be detected on the 10 remains attributed to Lembulus pella, even if no intentional perforation can be identified. All specimens present with circular holes with 
645

bevelled edges that can be attributed to predator gastropods. At the same time, the best preserved shells also exhibit notches located near the umbo that are consistent with deliberate suspension. The opportunistic use of natural holes is commonly documented in archaeological contexts (BarYosef Mayer et al. 2009; Cabral and Martins 2016).

All the above mentioned results support human involvement in collection, transportation, and modification (the latter for a part of the assemblage) of the shells uncovered at Grotta del Cavallo. If pierced specimens and intentionally broken or used tusks can be confidently associated with an ornamental role, unmodified shells can be interpreted as raw materials waiting to be used in bead production. Since natural accumulation of shells can be excluded, the occurrence of unpierced items which are not suitable for consumption, tusk shells which are not suitable for suspension, and waste products suggests that a systematic manufacturing process was taking place at the site. Considering the clustered distribution of shells illustrated above, the presence of an adornment manufacturing area could be proposed for the most recent phase (layer DI). This area was likely located in square H11 and, to a lesser extent, in square H7, where shells have been retrieved. In the oldest layers, shells were found in a different area of the cave. Here the retrieval of tusk distal portions not suitable for suspension is also documented, and is also possible to hypothesize breakage in situ, even if with lower levels of intensity and dimensional homogeneity.

\subsection{Bead making in the Uluzzian}

When looking at the other main Uluzzian sites found in Italy and Greece (e.g., Grotta della Cala, Grotta di Castelcivita, Klissoura Cave, Riparo Broion), we observe a uniform scenario (except for Castelcivita) exclusively characterized by shell ornaments, among which tusk shells are usually prevalent (Fiocchi 1998; Stiner 2010; Peresani et al. 2019a). Such a composition of ornamental assemblages testifies to the existence of a shared and widespread tradition across the Mediterranean. Clearly recurrent features and marked similarity between sites imply either common ancestry or 
cumulative mechanisms of cultural transmission and diffusion, processes that are commonly accepted for the Protoaurignacian (Vanhaeren and d'Errico 2006; Stiner et al. 2013).At Riparo Broion (Northern Italy), where the Uluzzian layers (SU 1f and 1g) have been recently dated to 44.4 - $42.8 \mathrm{ka}$ cal BP, a few finished shell beads have been retrieved (Appendix, Section X, Fig. S12-13). These consist of five scaphopods (4 Antalis vulgaris and 1 Antalis dentalis/inaequicostata) and a pierced gastropod (Teodoxus fluvialis; Peresani et al. 2019a). All tusk beads show clear signs of anthropogenic manipulation, documented by the occurrence of cut-marks on a specimen and welldeveloped suspension wear-traces on the whole of the sample (Peresani et al. 2019a). These beads are notably constrained in their size range, when compared with those from Cavallo. Noteworthy is the presence of notch fractures that can be related to suspension (Appendix, Section X, Fig. S13). In addition, the gastropod shows traces of intentional perforation and suspension (Peresani et al. 2019a). The distance of Riparo Broion from possible fossil outcrops and/or the coast suggests that the shells were brought to the site as finished products.

Moving to southern Italy, several mollusks $(n=78)$ were found in the Uluzzian layers of Grotta della Cala. These specimens belong to 25 different taxa (classes Gasteropoda, Bivalvia, Scaphopoda; Fiocchi 1998). Among them there are six pierced gastropods (H. sanguineum and T. pellucida), two perforated bivalves (Glycimeris nummaria) and 24 scaphopods. At a preliminary analysis, tusk shells show rounded edges and seem to be all finished beads with probable suspension traces. Klissoura Cave I (Peloponnesus, Greece) yielded 11tusk shells and several gastropods, especially Tritia neritea $(\mathrm{n}=7)$, and a few bivalves. The predominance of tusks and Tritia neritea draws an interesting parallel with the uppermost layers of Grotta del Cavallo, especially considering the temporal overlap between the two contexts (Douka et al. 2014).

The cave site of Castelcivita, located at the foot of the Alburni massif (southern Italy), stands out from this framework as it yielded, so far, only two fragmentary shells (bivalves) (Gambassini 1997). However, investigations at this site are still ongoing and the ornamental record might be enriched by further items. 
It is worth noting the marked resemblance between Uluzzian contexts and the Preaurignacian levels of Franchthi Cave (Peloponnesus, Greece) sealed by CI tephra (Farrand 2000; Fitzsimmons et al. 2013). Here a number of shells has been retrieved, but their poor state of preservation did not allow researchers to ascertain their use or the presence of perforation (Perlès 2019). The assemblage at Frachthi Cave mostly consists of inedible tusk shells and Tritia neritea, like in the case of Klissoura and Grotta del Cavallo DII-DI, both of which are used for ornament making in the following phases (Perlès 2019).

When ornaments of all Uluzzian contexts are considered at once a general trend over time can be identified in assemblage composition. The earliest phases (Cavallo layers EIII and EII-I, Broion) are characterized by scaphopods and rare pierced gastropods, whilst later phases (Cavallo layers DII and DI, Klissoura, Cala and maybe also Franchthi) show an increase in richness of species used for ornament production but still with a higher percentage of tusk shells, followed by gastropods (especially Tritia neritea). Among them $H$. sanguineum is marginally represented. In contrast, subsequent Upper Palaeolithic contexts display a marked preference for this species, which was consistently included in personal ornamental assemblages and exchanged over long distance across the Europe (Alvarez-Fernández 2006; Vanhaeren and d'Errico 2006; Peresani et al. 2019b). As far as bivalves are concerned, they seem to be considered less relevant until the latest Uluzzian phases. Ornament assemblage size in Uluzzian sites is also relevant, when compared with the coeval Châtelperronian, the only European techno-complex to have yielded conspicuous ornamental assemblages, composed of bone and ivory pendants as well as very sporadic shells (Zilhão 2007). Their size, however, is considerably smaller than that of the Uluzzian assemblages. The bulk of the Châtelperronian ornaments are from Grotte du Renne ( $n=35$, d'Errico et al. 1998), where uncertain integrity of the stratigraphic sequence made it difficult to accurately reconstruct the cultural provenance of some items (White 2002; Higham et al. 2010; but see contra Caron et al. 2011; Hublin et al. 2012). 
The other Châtelperronian sites yielded only a few ornaments (Zilhão 2007), but many of these deposits, such as Grotte des Fées, Roc de Combe and Trou Magrite, suffered from the intrusion of Aurignacian materials (Bordes and Labrot 1967; Rigaud 2001; Moreau 2003; Mellars et al. 2007; Zilhão et al. 2007). The occurrence of several tusk shells at Saint-Césaire is certainly of great interest (d'Errico et al.1998), but, regretfully, no further information is available on this material.

The other European transitional techno-complexes are characterized by sporadic findings (Kozlowski 1982; Hülle 1977; Zilhão 2007) which do not seem to support a pivotal role of nonperishable personal ornaments in the local material cultures.

Also worthy of note is the complete lack of tusks in the Initial Upper Palaeolithic (Emiran) assemblages of the Levant, where gastropods and bivalves are the only species used for ornamental purposes. To date, the most ancient tusk beads of this region are from layer E-E2 (ca 42. ka cal BP; Kuhn et al. 2009) of Üçağızlı Cave (Turkey; Stiner et al. 2002; Campbell 2017), containing an early Ahmarian assemblage (Stiner et al. 2013). In this area other scaphopods have been recovered at Manot Cave and Kebara, inside contexts with mixed Ahmarian and Aurignacian materials. The presence of such shells is currently interpreted as the result of influence by groups bearing European Aurignacian cultural elements (Bar Yosef-Mayer 2019). This evidence confirms the differences existing between Uluzzian and IUP contexts and is consistent with the lack of Uluzzianlike techno-complexes in the Near East (Moroni et al. 2013).

In ethnographic instances ornaments connote and, in some cases, identify the human groups who produce and wear them, thanks to the social, symbolic, cognitive and artistic values they embody. In this perspective adornment objects (including but not limited to shell beads) are elements of visual communication. For these reasons their widespread presence in the Uluzzian suggests a high degree of cohesion within and possibly between human groups. What the use of ornaments exactly symbolized in the Uluzzian mental template is difficult to say, even if we can hypothesize that these objects played a key role in defining and communicating the identity of the individual and/or the group to which the individual belonged - thus suggesting, in some way, the occurrence of a 
shared symbolic background. The systematic production and use of ornaments, in addition to other characteristics, markedly differentiate the Uluzzian from the Mousterian, as the occurrence of ornaments in the Middle Palaeolithic remains sporadic, despite some recent discoveries and researchers' increased interest for this debated issue (Zilhão et al. 2009; Peresani et al. 2011; Peresani et al. 2013; Romandini et al. 2014).

\section{Conclusion}

The widespread occurrence of shell beads in Uluzzian contexts supports the emergence of a wellestablished technology of bead making in Mediterranean Europe early as $45 \mathrm{ka}$, well before the onset of Aurignacian ornament productions across Europe. Uluzzian groups in Italy and Greece shared the same ornament traditions, and Grotta del Cavallo is the archaeological context that best explains this phenomenon. The Uluzzian sequence at this site yielded the most conspicuous amount of shell beads ever found in European transitional contexts. Analysing change over time in this assemblage allow us to document the presence of finished products and unfinished by-products, attesting to an increasing seek for dimensional regularity and serial production, as well as to the evidence for systematic ornament use. These features indicate that the Uluzzian bead making is fully comparable with the ornament productions typical of the Upper Palaeolithic, and push back the date for the beginning of systematic ornament use and manufacture in Europe to $45 \mathrm{ka}$

\section{Data availability}

Authors can confirm that all data and source codes for analyses are currently included as supplementary information files.

\section{Acknowledgements}

Acknowlodgements: We thank the Soprintendenza Archeologia, Belle Arti e Paesaggio per le Province di Brindisi, Lecce e Taranto for supporting our research in Apulia over the years. We 
express gratitude to prof. Palma di Cesnola and prof. Paolo Gambassini for giving permission to study the Uluzzian materials from their excavations at Grotta del Cavallo.

We are grateful to Luigi Romani for his help in taxonomic classification of scaphopods, to Lavinia Corbo who contributed to measuring specimens, and to Stefano Ricci who made photographic documentation of the shells from Grotta del Cavallo. We also acknowledge all the students who helped us in experimental tests (Francesco Antonini, Giulia Cappelletti, Margherita Gramigni, Simone Marzocca and Irene Mazza). A special thanks to Sem Scaramucci for his contribution in collecting tusks in Salento and for his precious advice. We are also grateful to the two anonymous reviewers for their careful reading of the manuscript and constructive comments. This project has received funding from the European Research Council (ERC) under the European Union's Horizon 2020 research and innovation program (grant agreement No 724046 - SUCCESS - http://www. ercsuccess.eu).

Author contributions: S.A., E.B., S.B and A.M. designed research; S.A. performed morphological and use-wear analysis. E.B. carried out statistical analysis. L.T carried out taphonomic and technological analysis. A.B., G.M., and L.T. made the taxonomic classification of the shells. A.M.B and L.M.F. carried out micropaleontological studies and F.L. and A.C. realized isotope analysis. Experimental tests were performed by S.A., D.A., F. Bo, C.F., G.M., G.O. and S.S. Paleoclimate and paleoecological conditions were described by F.Ba. V.S. collected present day tusk shells and reconstructed the palaeo-geographic conditions of the Uluzzian coastline. A.M., M.P., M.R. and A.R. provided archaeological data and contributed to the revision of the manuscript. S.A., E.B., A. M., A.B., V.S., L.M.F., A.M.B., M.R., F.L., F.Ba., L. T and S.B. wrote the paper with inputs from all co-authors.

Competing Interests: The authors declare no competing interests.

\section{References}


Abadia OM, Nowell A (2015) Palaeolithic Personal Ornaments: Historical Development and

Epistemological Challenges. J Archaeol Method Th 22: 952-979. https://doi.org/10.1007/s10816-

799

014-9213-Z

800

Álvarez Fernández E (2006) Los objetos de adorno-colgantes del Paleolítico superior y del 803

Mesolítico en la cornisa cantábrica y en el valle del Ebro: una visión europea. Unpublished PhD

803 thesis, Universidad de Salamanca

804

Arrighi S, Borgia V (2009) Surface Modifications of Flint Tools and Their Functional Meaning.

807

Bar-Yosef Mayer D (2008) Dentalium Shells Used by Hunter-Gatherers and Pastoralists in the 809 Levant. Archaeofauna 17:103-110

810

Bar-Yosef Mayer D (2019) Upper Paleolithic Explorers: The Geographic Sources of Shell Beads in Early Upper Paleolithic Assemblages in Israel. PaleoAnthropology 105-115. doi:10.4207/PA.2019.ART126

Bar-Yosef Mayer D E, Vandermeersch B, Bar-Yosef O (2009) Shells and ochre in Middle

Paleolithic Qafzeh Cave, Israel: indications for modern behavior. J Hum Evol 56 (3):307-314. doi:10.1016/j.jhevol.2008.10.005

Bar-Yosef O (2007) The archaeological framework of the Upper Paleolithic revolution. Diogenes 
825 Benazzi S, Douka K, Fornai C, Bauer CC, Kullmer O, Svoboda J, Pap I, Mallegni F, Bayle P, 826 Coquerelle M, Condemi S, Ronchitelli A, Harvati K, Weber GW (2011) Early dispersal of modern 827 humans in Europe and implications for Neanderthal behaviour. Nature 479: 525-528.

828 https://doi.org /10.1038/nature10617

829

830

831

832

833

Benazzi S, Slon V, Talamo S, Negrino F, Peresani M, Bailey SE, Sawyer S, Panetta D, Vicino G, Starnini E, Mannino MA, Salvadori PA, Meyer M, Pääbo S, Hublin JJ (2015) The Makers of the Protoaurignacian and Implications for Neandertal Extinction. Science 348: 793-6

Benghiat S, Komso D, Miracle PT (2009) An experimental analysis of perforated shells from the site of Sebrn Abri, Istria, Croatia. In: McCartan S, Schulting R, Warren G, Woodman P (eds) Mesolithic Horizons. Oxbow books, Oxford, pp 730-736

Bonnardin S (2007) From traces to function of ornaments: some Neolithic examples. In: Longo L, Skakun N (eds) "Prehistoric Technology” 40 Years Later. BAR Int. Ser. 1783, Archaeopress, Oxford, pp 297-308

Bordes F, Labrot J (1967) La stratigraphie du gisement de Roc de Combe (Lot) et ses implications. Bull Soc Préhist Fr LXIV (1): 15-28

Boscato P, Crezzini J (2012) Middle-Upper Palaeolithic transition in Southern Italy: Uluzzian macromammals from Grotta del Cavallo (Apulia). Quat Int 252: 90-98. https://doi.org/10.1016/j.quaint.2011.03.028 
Bosch MD, Buck L, Strauss A (2019) Location, location, location: Investigating Perforation

850 Locations in Tritia gibbosula Shells at Ksar 'Akil (Lebanon) Using Micro-CT Data.

851 PaleoAnthropology 52-63. https://doi.org/10.4207/PA.2019.ART123

852

Cabral JP, Martins JMS (2016) Archaeological Glycymeris glycymeris shells perforated at the umbo: Natural or man-made holes? J Archaeol Sci Rep 10: 474-482.

https://doi.org/:10.1016/j.jasrep.2016.11.008

856

Campbell G (2017) The Reproduction of Small Prehistoric Tusk Shell Beads. In: Bar-Yosef Mayer 859

D, Bonsall C, Choyke AM (eds) Not Just for Show: The Archaeology of Beads, Beadwork and Personal Ornaments, Oxbow Books, pp 168-224

860

Caron F, d'Errico F, Del Moral P, Santos F., Zilhão J (2011) The reality of Neandertal symbolic behavior at the Grotte du Renne, Arcy-sur-Cure, France. PLoS One 6(6): e21545. https://doi.org/10.1371/journal.pone.0021545

Charney N., Record S (2012) vegetarian: Jost Diversity Measures for Community Data. R package 866 version 1.2. https://CRAN.R-project.org/package=vegetarian

867 (2011) Marine mollusc exploitation in Mediterranean prehistory: An overview. Quat Int 239 (1-2): 86-103. doi:10.1016/j.quaint.2010.09.001 
d’Errico F, Zilhão J, Julien M, Baffier D, Pelegrin J (1998) Neanderthal Acculturation in Western Europe? A Critical Review of the Evidence and Its Interpretation. Curr Anthropol 39: 1-44

d'Errico F, Henshilwood C, Lawson G, Vanhaeren M, Tillier AM, Soressi M, Bresson F, Maureille B, Nowell A, Lakarra J, Backwell L, Julien M (2003a) Archaeological evidence for the emergence of language, symbolism, and music: an alternative multidisciplinary perspective. J World Prehist 17: $1-70$

d'Errico F, Julien M, Liolios D, Vanhaeren M, Baffier D (2003b) Many awls in our argument. Bone tool manufacture and use in the Châtelperronian and Aurignacian levels of the Grotte du Renne at Arcy-sur-Cure. In: Zilhão J, d'Errico F (Eds) The Chronology of the Aurignacian and of the Transitional Technocomplexes. Dating, Stratigraphies, Cultural Implications. Proceedings of Symposium 6.1 of the XIV Congress of the UISPP, Trabalhos de Arqueologia, vol. 33. Instituto Português de Arqueologia, Lisboa, pp 247-271

d'Errico F, Vanhaeren M, Barton N, Bouzouggar A, Mienis H, Richter D, Hublin JJ, McPherron SP, Lozouet P (2009) Additional evidence on the use of personal ornaments in the Middle Palaeolithic of North Africa. Proc Natl Acad Sci 106: 16501-16056. https://doi.org/10.1073/pnas.0903532106

d'Errico F, Borgia V, Ronchitelli A (2012) Uluzzian bone technology and its implications for the origin of behavioural modernity. Quat Int 259: 59-71 https://doi.org/10.1016/j.quaint.2011.03.039

d'Errico F, Banks WE (2013) Identifying Mechanisms behind Middle Paleolithic and Middle Stone Age Cultural Trajectories. Curr Anthropol 54 (8):371-387. https://doi.org/10.1086/673388 
d'Errico F, Backwell L (2016). Earliest evidence of personal ornaments associated with burial: the

Dimitrijević V (2014) The provenance and use of fossil scaphopod shells at the Late 904 Neolithic/Eneolithic site Vinča - Belo Brdo, Serbia. In: Szabó K, Dupont C, Dimitrijević V, 905 Gómez Gastélum L, Serrand N (eds) Archaeomalacology: Shells in the Archaeological Record 906 BAR International Series 2666, Archaeopress, Oxford, pp 33-41

907

Douka K, Higham, TF, Wood R, Boscato P, Gambassini P, Karkanas P, Peresani M, Ronchitelli A 909 (2014) On the chronology of the Uluzzian. J Hum Evol 68: 1-13.

https://doi.org/10.1016/j.jhevol.2013.12.007

Farrand WR (2000) Depositional History of Franchthi Cave, Sediments, Stratigraphy and

Chronology. With a Report on the Background of the Franchthi project by T.W. Jacobsen.

Excavations at Franchthi Cave, Greece, fasc. 12, Indiana University Press, Bloomington \& Indianapolis

Fiocchi C (1998) Contributo alla conoscenza del comportamento simbolico di Homo sapiens sapiens. Le conchiglie marine nei siti del Paleolitico superiore europeo: strategie di approvvigionamento, reti di scambio, utilizzo. Unpublished $\mathrm{PhD}$ thesis Scienze Antropologiche, Consorzio Universitario di Bologna, Ferrara, Parma 
Flas D (2011) The Middle to Upper Paleolithic transition in Northern Europe: the Lincombian-

Ranisian-Jerzmanowician and the issue of acculturation of the last Neanderthals. World Archaeol. di Castelcivita culture e ambiente, Electa, Napoli, pp 75-145

932

Giaccio B, Hajdas I, Isaia R, Deino A, Nomade S (2017) High-precision 14C and 40Ar/39Ar

Gravina B, Bachellerie F, Caux S, Discamps E, Faivre JP, Galland A, Michel A, Teyssandier N, Bordes JJ (2018) No Reliable Evidence for a Neanderthal-Châtelperronian Association at La Roche-à-Pierrot, Saint-Césaire. Sci Rep 8: 15134. https://doi.org/10.1038/s41598-018-33084-9 dating of the Campanian Ignimbrite (Y-5) reconciles the time-scales of climatic-cultural processes at $40 \mathrm{ka}$. Sci Rep 7: 45940

Gioia P (1990) An aspect of the transition between Middle and Upper Paleolithic in Italy: the Uluzzian. In: Farizy C (ed) Paléolithique moyen récent et Paléolithique supérieur ancien en Europe Ruptures et transitions: examen critique des documents archéologiques, APRAIF, Nemours, pp 241-250

Higham T, Jacobi R, Julien M, David F, Basell L, Wood R, Davies W, Ramsey CB (2010) Chronology of the Grotte du Renne (France) and implications for the context of ornaments and human remains within the Châtelperronian. Proc Natl Acad Sci 107(47): 20234-9. https://doi.org / 10.1073/pnas.1007963107 
Hoffmann DL, Angelucci DE, Villaverde V, Zapata J, Zilhão J (2018) Symbolic use of marine

shells and mineral pigments by Iberian Neandertals 115,000 years ago. Sci Adv 4(2).

953 https://doi.org / 10.1126/sciadv.aar5255

954

Hublin JJ (2015) The modern human colonization of western Eurasia: when and

where? Quat Sci Rev 118: 194-210. http://dx.doi.org/10.1016/j.quascirev.2014.08.011

957

Hublin JJ, Spoor F, Braun M, Zonneveld F, Condemi S (1996) A late Neanderthal associated with

Upper Palaeolithic artefacts. Nature 381: 224-226. https://doi.org/10.1038/381224a0

960

Hublin JJ, Talamo S, Julien M, David F, Connet N, Bodu P, Vandermeersch B, Richards MP

(2012) Radiocarbon dates from the Grotte du Renne and Saint-Césaire support a Neandertal origin

for the Châtelperronian, Proc Natl Acad Sci 109(46): 18743-18748;

964 https://doi.org/10.1073/pnas.1212924109

965

Hülle W M (1977) Die Ilsenhöhle unter Burg Ranis/Thüringen. Eine paläolitische Jägerstation.

Gustav Fischer, Stuttgart

968

Jost L (2006) Entropy and diversity. Oikos 113(2): 363-375. https://doi.org/10.1111/j.2006.0030-

Jost L (2007) Partitioning diversity into independent alpha and beta components. Ecology 88(10): 2427-2439. https://doi.org/10.1890/06-1736.1

Kozłowski J (ed) (1982) Excavation in the Bacho Kiro Cave (Bulgaria): Final Report. Polish

Scientific Publishers, Warsaw 
Molina K, Ünay E, Suata-Alpaslan F (2009) The early Upper Paleolithic occupations at Üçağızlı

Largiolli T, Martinis B, Mozzi G, Nardin M, Rossi D, Ungaro S (1969) Gallipoli. Note illustrative della Carta Geologica d'Italia. Poligrafica e Cartevalori, Ercolano (Napoli)

983

984

Lévêque F, Vandermeersch B (1980) Les découvertes de restes humains dans un horizon

985

castelperronien de Saint-Césaire (Charente-Maritime). Bull. de la Soc. Préhist. de Française 77 :

Leroi-Gourhan A (1964) Le geste et la parole (Vol 2). Albin Michel, Paris

989

990

Lugli F, Cipriani A, Peretto C, Mazzucchelli M, Brunelli D (2017) In situ high spatial resolution 87Sr/86Sr ratio determination of two Middle Pleistocene (ca $580 \mathrm{ka}$ ) Stephanorhinus hundsheimensis teeth by LA-MC-ICP-MS. Int J Mass Spectrom 412: 38-48.

993 https://doi.org/10.1016/j.ijms.2016.12.012

994

995 Mamouridis V, Cartes JE, Parra S, Fanelli E, Salinas JS (2011) A temporal analysis on the 996 dynamics of deep-sea macrofauna: influence of environmental variability off Catalonia coasts 997 (western Mediterranean). Deep Sea Res Part 1 Oceanogr Res Pap 58 (4): 323-337 998

999 McElreath R, Boyd R, Richerson PJ (2003) Shared norms and the evolution of ethnic markers. 1000 Curr Anthropol 44: 122-129. http://dx.doi.org/10.1086/345689 
Mellars P, Gravina B, Bronk-Ramsey C (2007) Confirmation of Neanderthal/Modern Human interstratification at the Châtelperronian type-site. Proc Natl Acad Sci 104: 3657-3662. https://doi.org/10.1073/pnas.0608053104

Moreau L (2003) Les éléments de parure au Paléolithique supérieur en Belgique. L'Anthropologie 107: 603-614

Moroni A, Boscato P, Ronchitelli A (2013) What roots for the Uluzzian? Modern behaviour in

Central-Southern Italy and hypotheses on AMH dispersal routes. Quat Int 316: 27-44.

1011 http://dx.doi.org/10.1016/j.quaint.2012.10.051

Moroni A, Ronchitelli A, Arrighi S, Aureli D, Bailey SE, Boscato P, Boschin F, Capecchi G, Crezzini J, Douka K, Marciani G, Panetta D, Ranaldo F, Ricci S, Scaramucci S, Spagnolo V, Benazzi S, Gambassini P (2018) Grotta del Cavallo (Apulia - Southern Italy). The Uluzzian in the mirror. J Anthropol Sci 96: 1-36. http://dx.doi.org/ 10.4436/jass.96004

9161-z

Nenadic O, Greenacre M (2007) Correspondence Analysis in R, with two- and three-dimensional graphics: The ca package. J Stat Softw 20 (3): 1-13. http://dx.doi.org / 10.18637/jss.v020.i03

Orchard WC (1929) Beads and beadwork of the American Indians. Salzwasser-verlag Gmbh, Paderborn 
Palma di Cesnola A (1965) Notizie preliminari sulla terza campagna di scavi nella Grotta del Cavallo (Lecce). Riv Sci Preistoriche 20: 291-302

Palma di Cesnola A (1966) Gli scavi nella Grotta del Cavallo (Lecce) durante il 1966. Riv. Sci. Preistoriche 21: 289-301

Palma di Cesnola A (1989) L’Uluzzien: Faciès italien du leptolithique archaïque. L'Anthropologie 93 (4): 783-812

Peharda M, Thébault J, Markulin K, Schöne BR, Janeković I, Chauvaud L (2017) Contrasting shell growth strategies in two Mediterranean bivalves revealed by oxygen-isotope ratio geochemistry: The case of Pecten jacobaeus and Glycymeris pilosa. Chem Geol. http://dx.doi.org/10.1016/j.chemgeo.2017.09.029

Peresani M, Fiore I, Gala M, Romandini M, Tagliacozzo A (2011) Late Neandertals and the intentional removal of feathers as evidenced from bird bone taphonomy at Fumane Cave 44 ky B.P., Italy. Proc Natl Acad Sci 108 (10): 3888-3893. https://doi.org/10.1073/pnas.1016212108

Peresani M, Vanhaeren M, Quaggiotto E, Queffelec A, d'Errico F (2013) An ochered fossil marine shell from the Mousterian of Fumane Cave, Italy. PLoS One 8 (7): e68572. http://dx.doi.org /10.1371/journal.pone.0068572

Peresani M, Cristiani E, Romandini M, 2016 The Uluzzian technology of Grotta di Fumane and its implication for reconstructing cultural dynamics in the Middle-Upper Palaeolithic transition of Western Eurasia. J Hum Evol 91: 36-56. https://doi.org/10.1016/j.jhevol.2015.10.012 
1055 Peresani M, Bertola S, Del Piano D, Benazzi S, Romandini M (2019a) The Uluzzian in the North 1056 of Italy. Insights around the new evidence at Riparo Broion Rockshelter. Archaeol Anthrop Sci. 1057 http:// doi.org/10.1007/s12520-018-0770-z

1059 Peresani M, Forte M, Quaggiotto E, Colonese AC, Romandini M, Cilli C, Giacobini G (2019b) 1060 Marine shell exploitation during the Aurignacian at Fumane Cave. PaleoAnthropology 64-81. 1061 doi:10.4207/PA.2019.ART124

1063 Perlès C (2019) Cultural Implications of Uniformity in Ornament Assemblages: Paleolithic and 1064 Mesolithic Ornaments From Franchthi Cave, Greece. PaleoAnthropology 196-207. doi:10.4207/PA.2019.ART131

Radovčić D, Sršen AO, Radovčić J, Frayer DW (2015) Evidence for Neandertal Jewelry:

1068 Modified White-Tailed Eagle Claws at Krapina. PLoSOne 10 (3): e0119802.

1069 https://doi.org/10.1371/journal.pone.0119802

1071 R Core Team (2018) R: A language and environment for statistical computing. R Foundation for 1072 Statistical Computing, Vienna, Austria URL https://www.R-project.org/ on Symbolism. PlosOne 9 (7): e101278. https://doi.org/10.1371/journal.pone.0101278 
1078 Ronchitelli A, Boscato P, Gambassini P (2009) Gli ultimi Neandertaliani in Italia: aspetti culturali. 1079 In: Facchini F, Belcastro G (eds) La Storia di Neandertal. Biologia e Comportamento. Jaka Book, 1080 Bologna, pp 257-288

1082 Rigaud JP (2001) A propos de la contemporanéité du Castelperronien et de l’Aurignacien dans le 1083 nord-est de l’Aquitaine: une révision des données et ses implications. In: Zilhâo J, Aubry T, 1084 Carvalho A (eds) Les premières hommes modernes de la Péninsule Ibérique. Actes du Colloque de 1085 la Commission VIII de 1’UISPP, Instituto Português de Arqueologia, Lisboa, pp 61-68

Ruppert J, Bernet JW (2001) Our Voices: Native Stories of Alaska and the Yukon. University of Toronto Press, Toronto

1090 Sano K, Arrighi S, Stani C, Aureli D, Boschin F, Fiore I, Spagnolo V, Ricci S, Crezzini J, Boscato 1091 P, Gala M, Tagliacozzo A, Birarda G, Vaccari L, Ronchitelli A, Moroni A, Benazzi S (2019) The 1092 earliest evidence for mechanically delivered projectile weapons in Europe, Nat Ecol Evol 3:14010931414.

1095 Shimek R, Steiner G (1997) Chapter 6. Microscopic anatomy of invertebrates. Volume 6B:

1096 Mollusca II, Wiley-Liss, Inc

Škardla P (2013) The Bohunician in Moravia and Adjoining Regions. Archaeology, Ethnology 
Stiner MC (1999) Palaeolithic mollusc exploitation at Riparo Mochi (Balzi Rossi, Italy): Food and ornaments from the Aurignacian through Epigravettian. Antiquity 73: 735-754. https://doi.org/10.1017/S0003598X00065492

Stiner MC (2010) Shell ornaments from the Upper Paleolithic through Mesolithic layers of Klissoura Cave 1 by Prosymna (Peloponnese, Greece). Eurasian Prehistory 7 (2): 287-308

Stiner MC (2014) Finding a Common Bandwidth: Causes of Convergence and Diversity in

Stiner MC, Pehlevan C, Sağir M Ŏzer I (2002) Zooarchaeological studies at Üçağızlı Cave:

Preliminary results on Paleolithic subsistence and shell ornaments. Araşturma Sonuçları Toplantısı

Taborin Y (1993) La parure en coquillage au Paléolithique. CNRS Éditions, Paris doi:10.1016/j.jas.2013.10.029

Vanhaeren M, d'Errico F (2001) La parure de l'enfant de La Madeleine (fouilles Peyrony). Un nouveau regard sur l'enfance au Paléolithique supérieur. Paléo 13 : 201-240 
1130 Vanhaeren M, d'Errico F (2006) Aurignacian ethno-linguistic geography of Europe revealed by 1131 personal ornaments. J Archaeol Sci 33(8): 1105-1128. doi:10.1016/j.jas.2005.11.017

1133 Vanhaeren M d'Errico F, Stringer C, James SL, Todd JA, Mienis HK (2006) Middle Palaeolithic 1134 shell beads in Israel and Algeria. Science 312: 1785-1787. https://doi.org/10.1126/science.1128139

1136 Vanhaeren M, d'Errico F, van Niekerk KL, Henshilwood CS, Erasmus RM (2013) Thinking 1137 strings: additional evidence for personal ornament use in the Middle Stone Age at Blombos Cave, 1138 South Africa. J Hum Evol 64: 500-517

Villa P, Pollarolo L, Conforti J, Marra F, Biagioni C, Degano I, Lucejko JJ, Tozzi C, Pennacchioni 1141 M, Zanchetta G, Nicosia C, Martini M, Sibilia E, Panzeri L (2018). From Neandertals to modern 1142 humans: New data on the Uluzzian. PLoS One 13: e0196786. doi:10.1371/journal.pone.0196786

1144 Welker F, Hajdinjak M, Talamo S, Jaouen K, Dannemann M, David F, Julien M, Meyer M, Kelso J, 1145 Barnes I, Brace S, Kamminga P, Fischer R, Kessler BM, Stewart JR, Pääbo S, Collins MJ, Hublin JJ 1146 (2016) Palaeoproteomic evidence identifies archaic hominins associated with the Châtelperronian 1147 at the Grotte du Renne. Proc Natl Acad Sci 113(40): 11162-11167.

1148 https://doi.org/10.1073/pnas.1605834113

1150 White R (1989) Visual thinking in the Ice Age. Sci Am 261(1): 92-99 
1152 White R (2002) Observations technologiques sur les objets de parure. In Schmider B (ed)

1153 L'Aurignacien de la Grotte du Renne. Les fouilles d'André Leroi-Gourhan à Arcy-sur-Cure,

1154 (Yonne), XXXIVe Supplément à Gallia Préhistoire, CNRS, Paris, pp 257-266

1155

1156 Zanchetta G, Giaccio B, Bini M, Sarti L (2018) Tephrostratigraphy of Grotta del Cavallo,

1157 Southern Italy: Insights on the chronology of Middle to Upper Palaeolithic transition in the

1158 Mediterranean. Quat Sci Rev 182: 65-77. https://doi.org /10.1016/j.quascirev.2017.12.014

1159

1160

1161

1162

1163

Zilhão J (2007) The emergence of Ornaments and Art: An Archaeological Perspective on the

Origins of "Behavioral Modernity”. J Archaeol Res 15: 1-54

Zilhão J, d'Errico F, Bordes JG, Lenoble A, Texier JP, Rigaud JP (2007) Grotte des Fées

(Châtelperron, Allier) ou une interstratification "Châtelperronien-Aurignacien” illusoire. Histoire

des fouilles, stratigraphie et datations. Paléo 19: 391-432

Zilhão J, Banks WE, d'Errico F, Gioia P (2015) Analysis of Site Formation and Assemblage

1171 Integrity Does Not Support Attribution of the Uluzzian to Modern Humans at Grotta del Cavallo.

$1172 \quad$ PLoS One 10: e0131181

$1173 \quad$ List of captions

1174 Fig. 1 Distribution of ornaments dated between ca. 45-39 ka across transitional contexts in Europe

1175 (sites with debated cultural attribution are represented here, see Discussion chapter). Pie radius is

1176 proportional to the total size of ornamental assemblages, while colours indicate the relative 
proportion contributed by different classes of items. 1) Saint-Césaire, 2) Quinçay, 3) Roc de Combe,

4) Caune de Belvis, 5) Cova Foradada, 6) Roche au Loup, 7) Grotte du Trilobite, 8) Grotte des Fées, 9) Grotte du Renne, 10) Trou Magrite, 11) Ilsenhöle Ranis, 12) Willendorf II, 13) Riparo Broion, 14) Grotta della Cala, 15) Grotta del Cavallo, 16) Klissoura Cave, 17) Franchthi Cave, 18) Bacho Kiro, 19) Brynzeny I

Fig. 2 Selection of shells from Grotta del Cavallo. a) Antalis sp. b) Tritia neritea. c) Antalis sp. d) Antalis sp. e) Tritia neritea. f) Homalopoma sanguineum. g) Columbella rustica. h) Phorcus turbinatus. i) Lembulus pella. j) Glycymeris sp.

Fig. 3 Type of fractures. Classification according to the type of fracture on the experimental material: rectilinear (a); oblique (b); symmetric irregular (c); asymmetric irregular (d); flute-mouth (e); notch (f). The bar is $1 \mathrm{~mm}$

Fig 4 Fracture degrees. Flute-mouth fracture with degree 1(a); flute-mouth fracture with degree 2 (b); flute-mouth fracture with degree 3 (c). The bar is $2 \mathrm{~mm}$

Fig 5 Waste products. Small apical portions interpreted as waste products

Fig.6 Traces of anthropogenic manipulation. Grotta del Cavallo. Layer DII - Tusk shell with cut marks (a) this kind of marks are very similar to those obtained experimentally by cutting tusk shells with a flint tool (b); Layer EIII - Tusk shell with a notch fracture showing well rounded (c) and polished edges (d); Layer EIII- Tusk shell showing a notch fracture with flattened (e) and polished 
areas (f); Layer EIII. Polishes inside a notch fracture (g); polishes inside a notch fracture produced during suspension experiment with a leather string (h)

Fig.7 Tusk shells inserted one into another from Grotta del Cavallo. Tusk shells inserted one into another from layer EII-I (a), split E-D (b) and layer DII (c). While the external surface of the tusks looks weathered (d), the inner, protected trait shows its original aspect (e)

Fig.8 Ochred shells from Grotta del Cavallo. Layer EIII- Ochre associated to a notch fracture (a). Ochre and black residues on the external surface of a specimen (b). Ochre on the apical end of a tusk. The edge is rounded and polished (c). Layer EII-I- Ochre located inside the shell and longitudinally spread (d)

Fig. 9 Diversity over time Graphs representing Gini-Simpson's Diversity index (a) and their Numbers equivalent (b; following Jost 2006) across the sequence of examined layers at Grotta del Cavallo

Fig. 10 Technological traces on gastropods from Cavallo. Layer EIII - Perforated Tritia neritea showing a notch consistent with suspension (a). Layer DII - Close-up of use-wear on the edge of the hole on a perforated Phorcus turbinatus (b). Layer DII - Rounded edges on perforated specimens of Tritia neritea (c-d). Layer DI - Perforation on a Columbella rustica, showing a notch and rounded edge (e). Layer DI - Sub-circular hole on a Homalopoma sanguineum (f) 
1222 Fig 11 Layer EII-I - Post-depositional holes on a Naticarius hebraeus (a). Layer DI -Traces of red 1223 pigment near the hole of a Lembulus pella (b). Layer DI - Residues of red pigment located inside 1224 the hole of a Tritia neritea (c). Layer DI - Heat cracks on a Tritia neritea (d)

1226 Fig.12 Graphic representation of notches location on edges of pierced shell found at Grotta del 1227 Cavallo during the Upper Uluzzian (DII-DI)

1229 Fig 13 Layer DI - L. pella with a round drilled hole showing a notch in quarter IV (a). Layer DI - $L$. 1230 pella with drilled holes showing notches in quarter IV and irregular flaking (b-c). Layer EIII - Hole 1231 due to predation on a Turritella sp. (d) 